Article

\title{
Quantifying the Impacts of Anthropogenic Activities and Climate Variations on Vegetation Productivity Changes in China from 1985 to 2015
}

\author{
Shahid Naeem ${ }^{1,2}$, Yongqiang Zhang ${ }^{1,2, *(\mathbb{D} \text {, Jing Tian }}{ }^{1,2}$, Faisal Mueen Qamer ${ }^{3}$, Aamir Latif ${ }^{2}$ \\ and Pranesh Kumar Paul 1,2 (D) \\ 1 Key Laboratory of Water Cycle and Related Land Surface Processes, Institute of Geographic Sciences and \\ Natural Resources Research, Chinese Academy of Sciences, Beijing 100101, China; \\ shahidn@igsnrr.ac.cn (S.N.); tianj.04b@igsnrr.ac.cn (J.T.); praneshkp@igsnrr.ac.cn (P.K.P.) \\ 2 University of Chinese Academy of Sciences (UCAS), Beijing 101408, China; aamir.latif@igsnrr.ac.cn \\ 3 International Center for Integrated Mountain Development (ICIMOD), Kathmandu 44700, Nepal; \\ Faisal.Qamer@icimod.org \\ * Correspondence: zhangyq@igsnrr.ac.cn; Tel.: +86-10-6485-6515
}

Received: 21 February 2020; Accepted: 28 March 2020; Published: 31 March 2020

\begin{abstract}
Accurate assessment of vegetation dynamics provides important information for ecosystem management. Anthropogenic activities and climate variations are the major factors that primarily influence vegetation ecosystems. This study investigates the spatiotemporal impacts of climate factors and human activities on vegetation productivity changes in China from 1985 to 2015. Actual net primary productivity (ANPP) is used to reflect vegetation dynamics quantitatively. Climate-induced potential net primary productivity (PNPP) is used as an indicator of climate change, whereas the difference between PNPP and ANPP is considered as an indicator of human activities (HNPP). Overall, $91 \%$ of the total vegetation cover area shows declining trends for net primary productivity (NPP), while only 9\% shows increasing trends before 2000 (base period). However, after 2000 (restoration period), $78.7 \%$ of the total vegetation cover area shows increasing trends, whereas $21.3 \%$ of the area shows decreasing trends. Moreover, during the base period, the quantitative contribution of climate change to NPP restoration is 0.21 grams carbon per meter square per year $\left(\mathrm{gC} \mathrm{m}^{-2} \mathrm{yr}^{-1}\right)$ and to degradation is $2.41 \mathrm{gC} \mathrm{m}^{-2} \mathrm{yr}^{-1}$, while during the restoration period, climate change contributes 0.56 and $0.29 \mathrm{gC} \mathrm{m}^{-2} \mathrm{yr}^{-1}$ to NPP restoration and degradation, respectively. Human activities contribute 0.36 and $0.72 \mathrm{gC} \mathrm{m}^{-2} \mathrm{yr}^{-1}$ during the base period, and 0.63 and $0.31 \mathrm{gC} \mathrm{m}^{-2} \mathrm{yr}^{-1}$ during the restoration period to NPP restoration and degradation, respectively. The combined effects of climate and human activities restore 0.65 and $1.11 \mathrm{gC} \mathrm{m}^{-2} \mathrm{yr}^{-1}$, and degrade 2.01 and $0.67 \mathrm{gC} \mathrm{m}^{-2} \mathrm{yr}^{-1}$ during the base and restoration periods, respectively. Climate factors affect vegetation cover more than human activities, while precipitation is found to be more sensitive to NPP change than temperature. Unlike the base period, NPP per unit area increases with an increase in the human footprint pressure during the restoration period. Grassland has more variability than other vegetation classes, and the grassland changes are mainly observed in Tibet, Xinjiang, and Inner Mongolia regions. The results may help policy-makers by providing necessary guidelines for the management of forest, grassland, and agricultural activities.
\end{abstract}

Keywords: anthropogenic activities; climate variations; vegetation productivity; base period; restoration period 


\section{Introduction}

Climate fluctuations and anthropogenic activities are the two major drivers of terrestrial ecosystem changes [1,2]. Abnormal climate variations have been coupled with the negative effects of human activities over the previous few decades, resulting in a series of environmental and ecological problems, such as air pollution, biodiversity losses, soil erosion, and vegetation ecosystem degradation [3]. Therefore, quantifying and separating the influences of these factors on vegetation ecosystems by emphasizing the dynamic variations in terrestrial ecosystems is an important research direction [4-6]. Vegetation is a key component of terrestrial ecosystems, and plays a prominent part in regulating the carbon balance, adapting land surface conditions, and emulating regional anthropogenic activities $[7,8]$. An ample number of studies have already been conducted on vegetation change and their driving factors (i.e., human activities and climatic variations) in recent years to investigate the vegetation dynamics at both regional and global scales $[9,10]$.

The impact of climatic fluctuations on vegetation ecosystems is a global concern. During the last few decades, the temperature of the globe has increased rapidly. Consequently, the frequency of rainfall events is predicted to increase at the same rate, especially in humid regions [11-13]. Previous studies have found that the temperature increase extends the length of the growing season, and thus supports an increase in productivity of vegetation ecosystems [14,15]. Conversely, Zhang et al. [16-18] claim that temperature contributes negatively to vegetation productivity. As vegetation responds differently to different climatic factors, it is essential to quantify the response of temperature and precipitation to vegetation productivity, accounting for spatiotemporal heterogeneity. Human activities also contribute strongly to vegetation dynamics and influence the vegetation ecosystems both positively and negatively. Recently, China has experienced serious environmental issues due to vegetation degradation. Those environmental problems are mainly triggered by overcultivation and overgrazing in environmentally complex and ecologically fragile regions of the country $[19,20]$. To restore the vegetation coverage, as well as productivity, and to minimize the human pressure on the environment, a series of vegetation-related policies were introduced by China. The Grain for Green Program launched in 1999 is one of the most prominent initiatives [21]. The major objective of all the vegetation-related projects is to increase the vegetation area, either by planting trees or by converting the bare land and wasteland into grassland [22]. Some vegetation conservation programs were also introduced to support ecological restoration. For example, the Grazing Withdrawal Program (GWP) was introduced in 2003 to minimize the grazing pressure on grassland ecosystems by employing cultivated pastures through forbidding grazing [23]. However, in some areas of China, the effects of such ecological and conservation programs have still not been quantified. Some studies indicate that human activities play a negative role in vegetation dynamics during the base period, including rapid construction, overgrazing, and deforestation. However, they contribute positively during the restoration period because of afforestation and land use planning. Therefore, both human activities, as well as climate change, can alter vegetation statistics significantly $[15,24,25]$.

Recently, many studies have documented that the comparison of actual vegetation productivity and potential vegetation productivity determines the human appropriation of vegetation productivity. Therefore, it is assumed that the difference between potential and actual productivities of vegetation represents the anthropogenic impacts [26]. Several researchers have followed the vegetation productivity difference method to quantify and separate the contributions of human activities and climate factors. Using net primary productivity (NPP) as an indicator of vegetation, previous studies indicate an exponential increase in vegetation productivity in China during the last couple of decades $[27,28]$. NPP is a very important indicator of vegetation growth status and exerts a significant influence on the carbon cycle of the global biosphere [14,29]. By definition, NPP represents the amount of carbon fixed through the process of photosynthesis by plants per unit of space and time. NPP is more sensitive to anthropogenic factors and climate variations than other vegetation indicators, precisely, reflect the responses of vegetation growth to human activities and climate change [30,31]. In particular, climate-induced potential NPP (PNPP) signifies the potential climatic conditions of vegetation growth 
without human interruption. Actual NPP (ANPP) is controlled by both human activities and climatic factors and indicates true conditions of vegetation growth. Therefore, the difference between PNPP and ANPP (PNPP-ANPP) is used to define human-induced NPP (HNPP) [28,32]. Thus, vegetation growth variations can be determined at a pixel scale by comparing the temporal variations of PNPP, ANPP, and HNPP [33].

Previous literature is quantitatively discriminated relative contributions of climatic factors and human activities in vegetation change using the NPP-based scenario simulation method. This method is supposed to achieve reasonable accuracy, as described in several studies [34]. For example, Xu et al. [23] studied the relative contributions of anthropogenic activities and climate change to assess the grassland dynamics of the Qinghai-Tibet Plateau at different time scales and used the scenario simulation method based on three types of NPP trends. Similarly, Zhang et. al. [35] applied the same method to investigate the major factors of grassland dynamics in Xinjiang. Furthermore, Yang et. al. [36] and Gang et al. [37] applied the scenario simulation method on both regional and global scales and indicated that the NPP-based scenario simulation method can successfully be applied for quantitative evaluation of the relative contribution of anthropogenic factors and climate variations in grassland dynamics at any scale.

To provide better quality of living conditions for human well-being, vegetation restoration and conservation is very important to deal with environmental and ecological issues in a country, which are mainly triggered by climate and human factors. Although several studies have already been conducted to quantify the relative contributions of climate variations and anthropogenic factors, relatively less attention has been paid to evaluating the effectiveness of these ecological restoration programs at the national level, considering all of the green infrastructure in China. Therefore, it is important to rigorously monitor the vegetation restoration activity to investigate the efficiency of these programs. In view of the above research gap, this study investigates 31-year vegetation productivity dynamics across China, considering all the green areas in the country. The study period is divided into a base period and restoration period to evaluate the effectiveness of vegetation conservation and restoration policies. The specific objectives of this study are: (1) to evaluate the spatiotemporal change pattern and sustainability trends of vegetation growth; (2) to identify the contributions of climate change and anthropogenic activities to vegetation productivity change; (3) to classify the roles of individual climatic parameters and human footprint pressure in vegetation dynamics. The work is done for both the base period (1985-1999) and restoration period (2000-2015). The findings of this study can provide a theoretical reference to assist policy-makers for the optimized management of green land and accomplish the sustainable use of ecological resources.

\section{Materials and Methods}

\subsection{Data}

\subsubsection{Climate Data}

The China Meteorological Forcing Datasets (CMDF) product is used for climatic parameters, including accumulative annual precipitation and mean annual air temperature (http://data.tpdc.ac. cn/en/data/8028b944-daaa-4511-8769-965612652c49/) [38]. CMDF is a gridded product with a spatial resolution of 0.1 degrees and a temporal resolution of 3 hours. The air temperature data are developed by merging the Princeton forcing data and the observed data from 740 ground stations covered by the China Meteorological Department (CMD). The precipitation data are produced by combining the CMD records with the Global Land Data Assimilation System (GLDAS) precipitation data from 1979 to 1998, and the Tropical Rainfall Measuring Mission (TRMM) rainfall product (3B42) for the period ranging 1998 to 2018 [39]. These datasets have already been used in previous studies to examine the vegetation response to climate variations [40,41]. The datasets are converted to annual records (mean annual temperature and annual accumulative precipitation) and resampled to $1 \mathrm{~km}^{2}$ spatial resolution 
by applying the nearest neighborhood algorithm to meet the cell size of the NPP product. Figure 1 shows the spatial patterns of mean annual records of climate data for base and restoration periods.
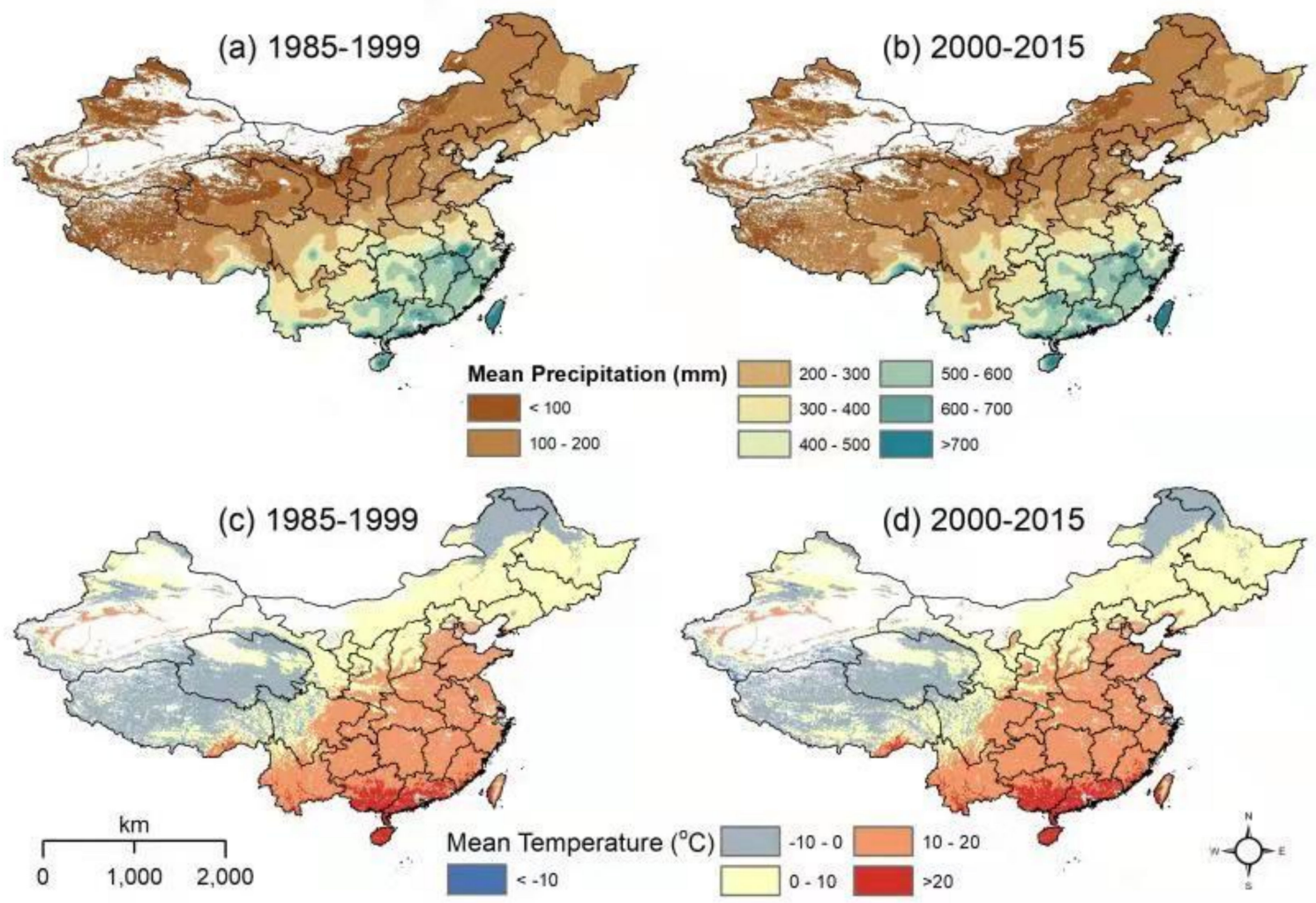

Figure 1. Climate factors used for this study: $(\mathbf{a}, \mathbf{b})$ mean precipitation base and restoration periods; $(\mathbf{c}, \mathbf{d})$ mean temperature for base and restoration periods.

\subsubsection{Human Footprint Data}

Human footprints (HFP) describe the intensity of human influence on terrestrial environments. The recently published HFP (https://www.nature.com/articles/sdata201667) datasets are used to investigate the relationship between human influence and net vegetation productivity changes [42] for both base and restoration periods. This is a globally-standardized gridded dataset at a spatial resolution of $1-\mathrm{km}^{2}$ for the years 1993 and 2009. The values of HFP data range from 0 to 64 , whereby a lower value corresponds to the low intensity of human influence and vice versa. Higher values are observed in cities. However, this study was conducted only for vegetation cover and neglects most of the city areas (non-vegetated area). Therefore, the HFP values for this study range from 0 to 36 . This system has already been used to explore the impacts of human activities on eco-environmental changes, including vegetation changes [43] and biodiversity loss [44]. The 1993 HFP data are used for base period, whereas the 2009 HFP data are used for the restoration period. Although these datasets are not compatible with the study period, they can provide an overall estimation of human impacts on vegetation productivity dynamics for both periods. The spatial patterns of HFP datasets are shown in Figure 2. 


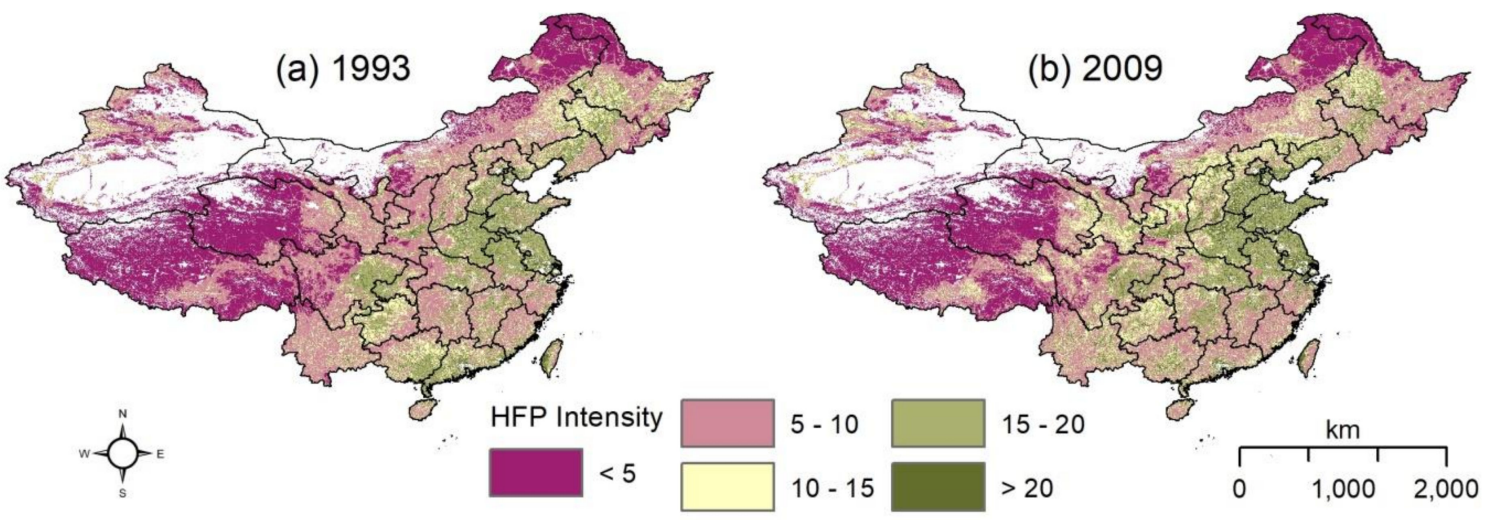

Figure 2. Human footprint intensity (HFP): (a,b) HFP for 1993 and 2009, respectively.

\subsubsection{Vegetation Cover Data}

To obtain the vegetation area, a vegetation cover map for China was acquired from the MCD12Q1 moderate-resolution imaging spectro-radiometer (MODIS) product. As described earlier, the vegetation of China increased significantly after the implementation of the Grain for Green Program; therefore, the product was downloaded for the year 2015 to account for the maximum possible vegetation area for the analysis. MCD12Q1 encloses five classification schemes, while the MODIS land cover product for the year 2015 was reclassified according to the classification system developed by the International Geosphere-Biosphere Program (IGBP) for this study $[13,45,46]$. The IGBP scheme classified the land cover into 17 classes, with 11 natural vegetation and three mosaic vegetation classes. The MCD12Q1 land cover product was reclassified to obtain three major vegetation classes: mixed forestland, mixed grassland, and mixed cropland. The reclassification scheme is given in the Table 1, and the spatial distribution of the vegetation classes is shown in Figure 3.

Table 1. Reclassification of the moderate-resolution imaging spectro-radiometer (MODIS) product (MCD12Q1).

\begin{tabular}{cc}
\hline International Geosphere-Biosphere Program (IGBP) Scheme & Reclassified Classes \\
\hline Evergreen Needleleaf Forest, Evergreen Broadleaf Forest, Deciduous & Mixed Forestland \\
Needleleaf Forest, Deciduous Broadleaf Forest, Mixed Forest & \\
Closed Shrublands, Open Shrublands, Woody Savannas, Savannas, & Mixed Grassland \\
Grasslands, Barren or Sparsely Vegetated, Permanent/Herbaceous Wetlands & Mixed Cropland \\
Croplands, Cropland/Natural Vegetation Mosaic & Non-vegetated land \\
\hline
\end{tabular}




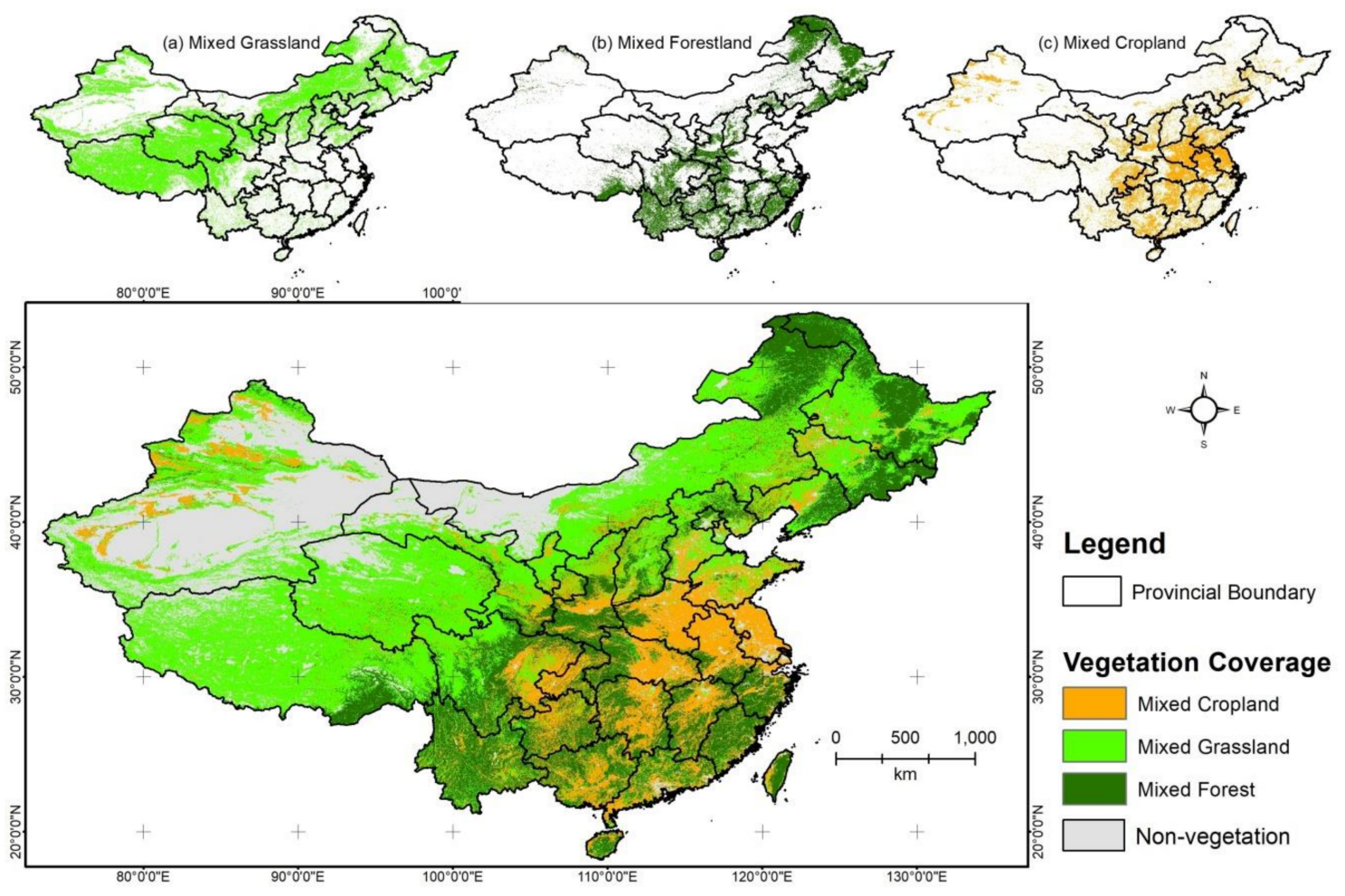

Figure 3. MODIS land cover product of China reclassified into three major classes.

\subsubsection{Net Primary Productivity (NPP) Data}

The monthly actual net primary productivity (ANPP) product (ChinaNPP_1985_2015) of China's terrestrial ecosystems at $1 \mathrm{~km}^{2}$ spatial resolution for 1985-2015 was used for this study [47]. ANPP data were downloaded from http://www.geodoi.ac.cn, and then monthly images were aggregated to an annual product to obtain total annual ANPP in grams carbon per meter square per year $\left(\mathrm{gC} \mathrm{m}^{-2} \mathrm{yr}^{-1}\right)$. These data were produced using the Carnegie-Ames-Stanford approach (CASA) model, together with the meteorological station data, making sure the same CMDF data source was used to calculate ANPP and PNPP. The ANPP data were validated by comparing them with simulated and measured data published in different articles. These data were preferred over the MODIS NPP product (MOD17A3) to consider the base period, as MODIS data are not available before the year 2000. The CASA model was applied using the following equation:

$$
\operatorname{NPP}_{(x, t)}=\operatorname{APAR}_{(x, t)} \times \varepsilon_{(x, t)}
$$

where $\operatorname{NPP}_{(x, t)}$ is the NPP value of a pixel $x$ at time $t\left(g C m^{-2}\right), A P A R_{(x, t)}$ is the value of the photosynthetically active radiation of a pixel $x$ at time $t\left(M J \mathrm{~m}^{-2}\right)$, and $\varepsilon_{(x, t)}$ is the value of the light energy use efficiency of a pixel $x$ at time $t$.

The absorbed photosynthetically active radiation (APAR) was calculated using the following equation [48]:

$$
\operatorname{APAR}_{(x, t)}=S O L_{(x, t)} \times F P A R_{(x, t)} \times 0.5
$$

where $\operatorname{SOL}(x, t)$ is the solar radiation value of pixel $x$ at time $t\left(\mathrm{MJ} / \mathrm{m}^{2}\right), \operatorname{FPAR}(x, t)$ represents the incoming fraction of photosynthetically active radiation absorbed by vegetation at pixel $x$ at time $t$, and the constant (0.5) is a fraction of solar radiation utilized by green vegetation.

Due to limitations of long term data availability, $F P A R_{(x, t)}$ was calculated using two different data sources: advanced very high-resolution radiometer (AVHRR) data were used to determine $F P A R_{(x, t)}$ 
from 1985 to February 2000, and MODIS data were used to determine $F P A R_{(x, t)}$ from March 2000 to 2015. The calculations were made based on the following equation [47]:

$$
\operatorname{FPAR}_{(x, t)}=\min \left[\frac{\left(S R_{(x, t)}-S R_{(x, t) \min }\right)}{\left(S R_{(x, t) \max }-S R_{(x, t) \min }\right)}, 0.95\right]
$$

where $S R_{(x, t)}$ is a simple ratio of location $x$ in time $t$, while $S R_{(x, t) \min }$ and $S R_{(x, t) \max }$ are minimum and maximum values or $S R$, respectively.

$$
S R_{(x, t)}=\frac{\left(1+N D V I_{(x, t)}\right)}{\left(1-N D V I_{(x, t)}\right)}
$$

where $\operatorname{NDVI}_{(x, t)}$ is the pixel value of NDVI at time $t$.

The light energy use efficiency $\varepsilon_{(x, t)}$ was calculated using the following equation:

$$
\varepsilon_{(x, t)}=T_{\varepsilon 1(x, t)} \times T_{\varepsilon 2(x, t)} \times W_{\varepsilon(x, t)} \times \varepsilon^{*}
$$

where $T_{\varepsilon 1(x, t)}$ and $T_{\varepsilon 2(x, t)}$ are the low and high effects of temperature on light energy conversion, respectively; $W_{\varepsilon(x, t)}$ is the water stress; $\varepsilon^{*}$ is the maximum possible light energy use efficiency; and an $\varepsilon^{*}$ value of 0.389 is used for AVHRR data, while 0.55 is used for MODIS data.

The ANPP product was further validated using ChinaFLUX tower data and field measurements of three forest sites.

The selected sites for the field measurements included Qilian Mountain, Changbaishan Natural Reserve, and Dunhua County. The Changbaishan Natural Reserve and Dunhua County are located in Jilin province and Qilian Mountain is in Gansu province, as shown in Figure 4a-c. The field experiments were conducted in late August or early September for the years of 2002, 2003, and 2004.

The empirical relationship between above ground biomass $(\mathrm{W})$, diameter at breast height (DBH) and tree height $(\mathrm{H})$ was used to calculate biomass for different trees [49]. The equation is given below:

$$
W=a\left(D B H^{2} H\right)^{b} \text { or } W=a(D B H)^{b}
$$

where $a$ and $b$ are the parameters of the equation.

The structural parameters ( $\mathrm{H}$ and $\mathrm{DBH}$ ) were collected for each tree in each sample plot, where 10, 14, and 10 plots were selected, respectively, to measure the biomass [50]. The biomass of each sample plot was calculated using a species-specific formula of relative tree growth [51]. The ANPP $\left(\mathrm{gC} \mathrm{m}^{-2}\right.$ year $\left.{ }^{-1}\right)$ for each sample plot was then obtained based on the biomass difference between two successive years. A strong relationship $\left(R^{2}\right.$ value of 0.84$)$ between simulated and measured ANPP values was found, as shown in Figure $4 \mathrm{~b}$.

The ANPP product was also validated using ChinaFLUX tower measurements. The data of 45 sites were obtained from http://www.cnern.org.cn/data/initDRsearch?classcode=DPAPER. The selected sites had at least one year of continuous measurements. Due to the footprint issues, the simulated ANPP pixel values were extracted using a $3 \times 3$ pixel window around the flux tower. The $3 \times 3$ pixel window method improves the spatial agreement, and has already been used in a few studies $[52,53]$. The mean values of $3 \times 3$ windows were then plotted against flux tower ANPP measurements, as shown in Figure $4 \mathrm{c}$. The $\mathrm{R}^{2}$ value between flux tower ANPP measurements and simulated ANPP product was calculated to be 0.74 , indicating a good relationship between measured and estimated ANPP. 

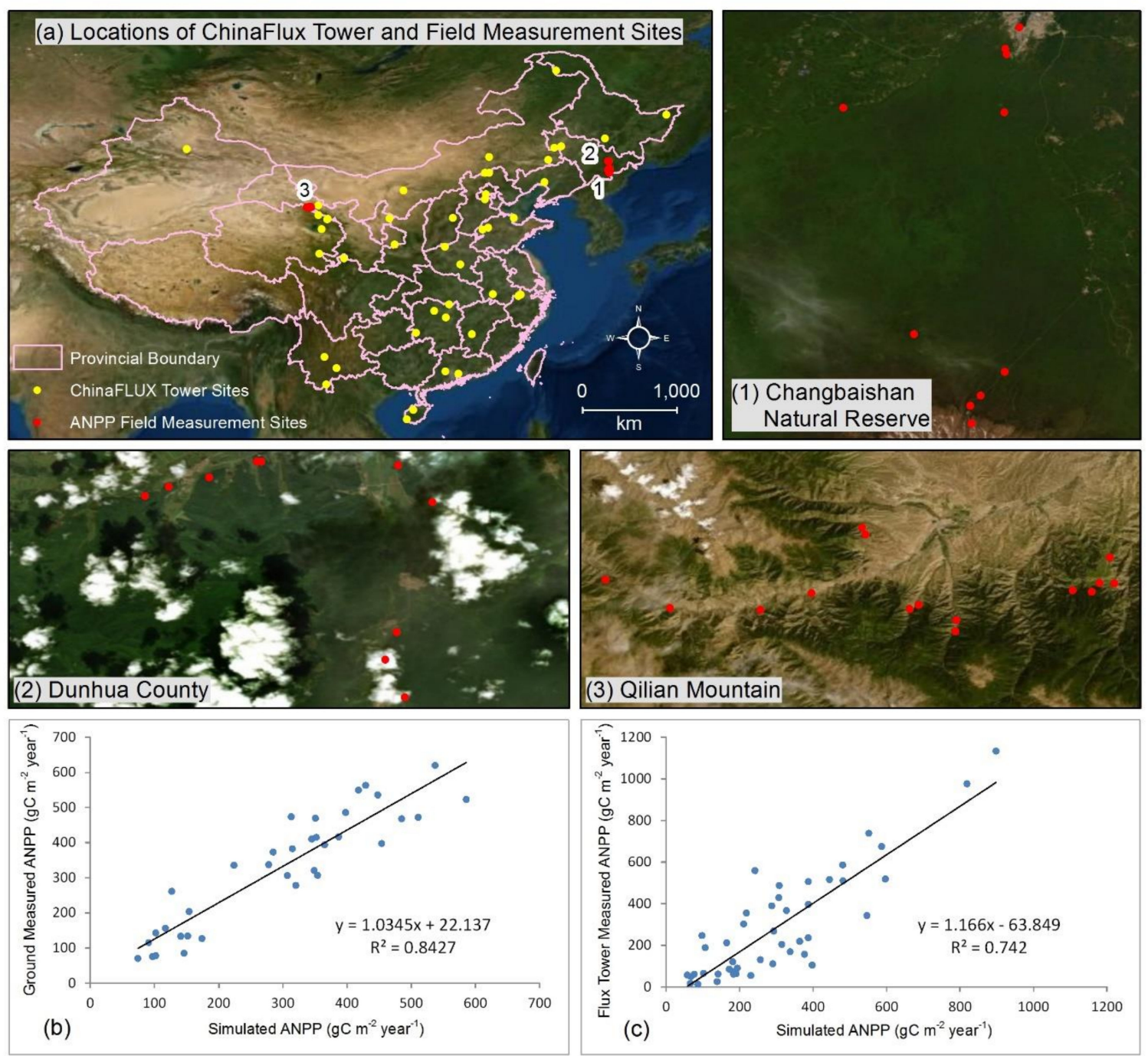

Figure 4. (a) The locations of ChinaFLUX tower and field measurement sites. (1-3) The three sample sites selected for field experiments. (b) The measurements from the 3 sample sites with the simulated actual net primary productivity (ANPP). (c) Comparison of the 45 flux tower measuresments with the simulated ANNP.

\subsection{Methodological Framework}

The Figure 5 illustrates the overall methodological framework used for this study. Three types of datasets were used for this study: NPPs, climate data, and human footprint data. The monthly ANPP product (ChinaNPP_1985_2015) of China's terrestrial ecosystems at $1 \mathrm{~km}^{2}$ spatial resolution for 1985-2015 was used for this study (Section 2.1.4). PNPP was derived using the Thornthwait Memorial (TM) model (Section 2.2.1), whereas HNPP was taken as the difference between PNPP and ANPP. The impacts of climate and human factors were investigated based on 8 scenarios by comparing the slopes of ANPP, PNPP, and HNPP (Section 2.2.2). The relative contributions of climatic factors to NPP change were determined by calculating the pixel-based Pearson's correlation of ANPP with temperature and precipitation, and were analyzed based on 8 scenarios (Section 2.2.4). 


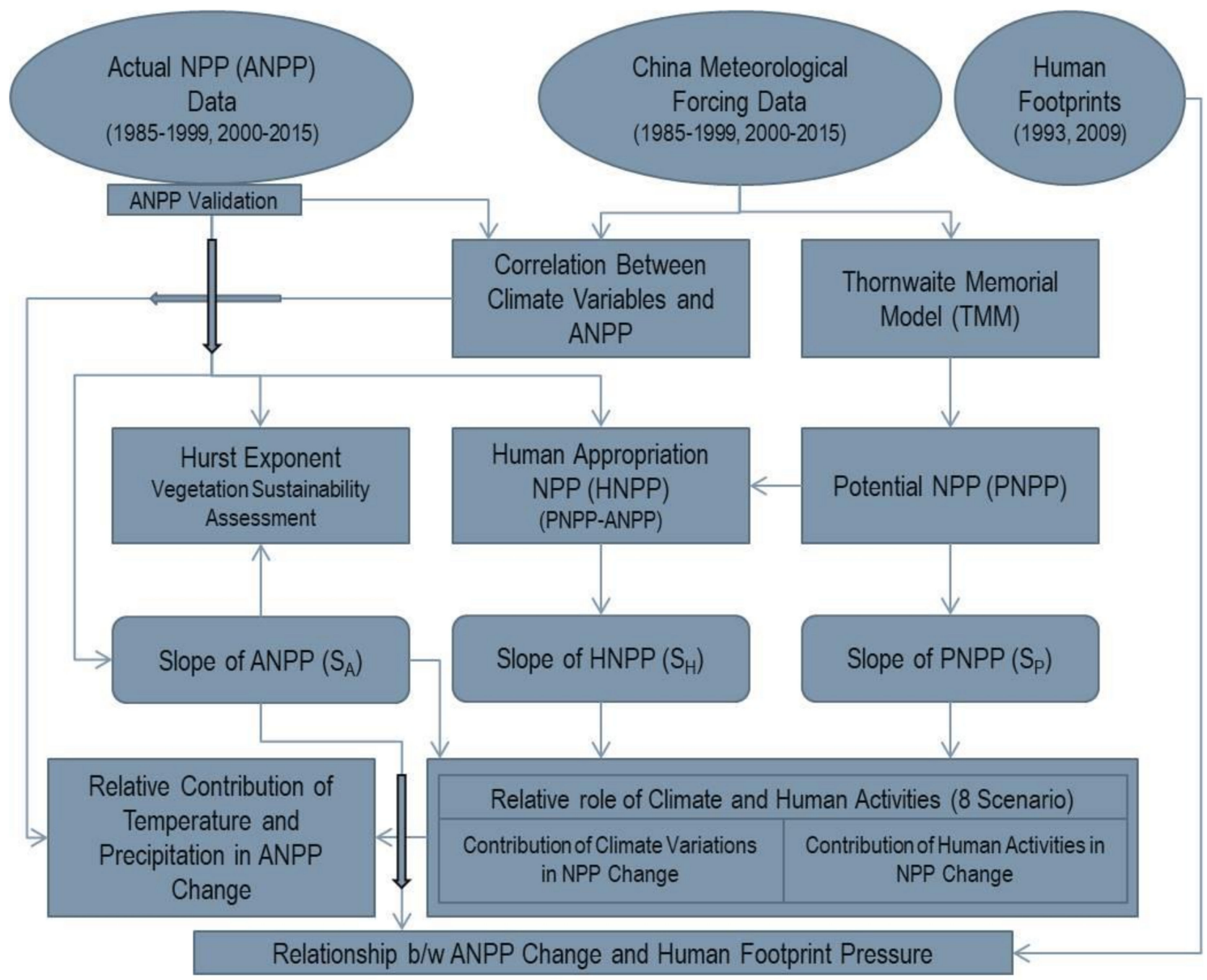

Figure 5. Methodological framework adopted for this study. NPP, net primary productivity.

\subsubsection{PNPP and HNPP Calculation}

The climate-influenced potential net primary productivity (PNPP) was estimated using the Thornthwaite memorial (TM) model. The TM model is a modified version of the Miami model, and it is a more accurate approach than the Miami model. It is based on the climatic data used in the Miami model and was developed using Thornthwaite's potential evaporation model [54]. The TM model employs the connection between carbon uptake and evapotranspiration to calculate pixel values of PNPP using temperature and precipitation as inputs. The basic principle of TM-model-based PNPP estimation is expressed in the following equation:

$$
\begin{aligned}
P N P P & =3000\left[1-e^{0.0009695(v-20)}\right] \\
v & =\frac{1.05 r}{\sqrt{1+\left(1+\frac{1.05 r}{L}\right)^{2}}} \\
L & =3000+25 t+0.05 t^{3}
\end{aligned}
$$

where PNPP indicates total annual potential NPP $\left(\mathrm{gC} \mathrm{m}^{-2} \mathrm{y}^{-1}\right), v$ is the average annual actual evapotranspiration $(\mathrm{mm}), L$ is the average annual potential evapotranspiration, $r$ is the total annual precipitation $(\mathrm{mm})$, and $t$ is the mean annual temperature $(\mathrm{C})$.

The saturation value of dry matter (DM) cannot exceed $3000 \mathrm{gDMm}^{-2} \mathrm{year}^{-1}$. In principal, the TM model estimates PNPP values by employing the relationship between carbon uptake and evapotranspiration. Temperature and precipitation are used as inputs for the calculation of evapotranspiration. A thorough explanation of this model is discussed by Lieth $[27,54,55]$ in detail. 
The human-induced NPP (HNPP) is estimated by calculating the difference between PNPP and ANPP $[27,32,35-37,56]$, as expressed below

$$
H N P P=P N P P-A N P P
$$

The HNPP value is shown in $\mathrm{gC} \mathrm{m}^{-2} \mathrm{yr}^{-1}$; the negative values represent NPP gain due to human activities, whereas the positive values represent a loss in NPP due to human activities [27]. In contrast, positive values of ANPP and PNPP represent NPP gain, while negative values of ANPP and PNPP represent NPP losses in $\mathrm{gC} \mathrm{m}^{-2} \mathrm{yr}^{-1}$. The spatial patterns of ANPP, PNPP, and HNPP for all vegetation classes are shown in Figures 6 and 7.

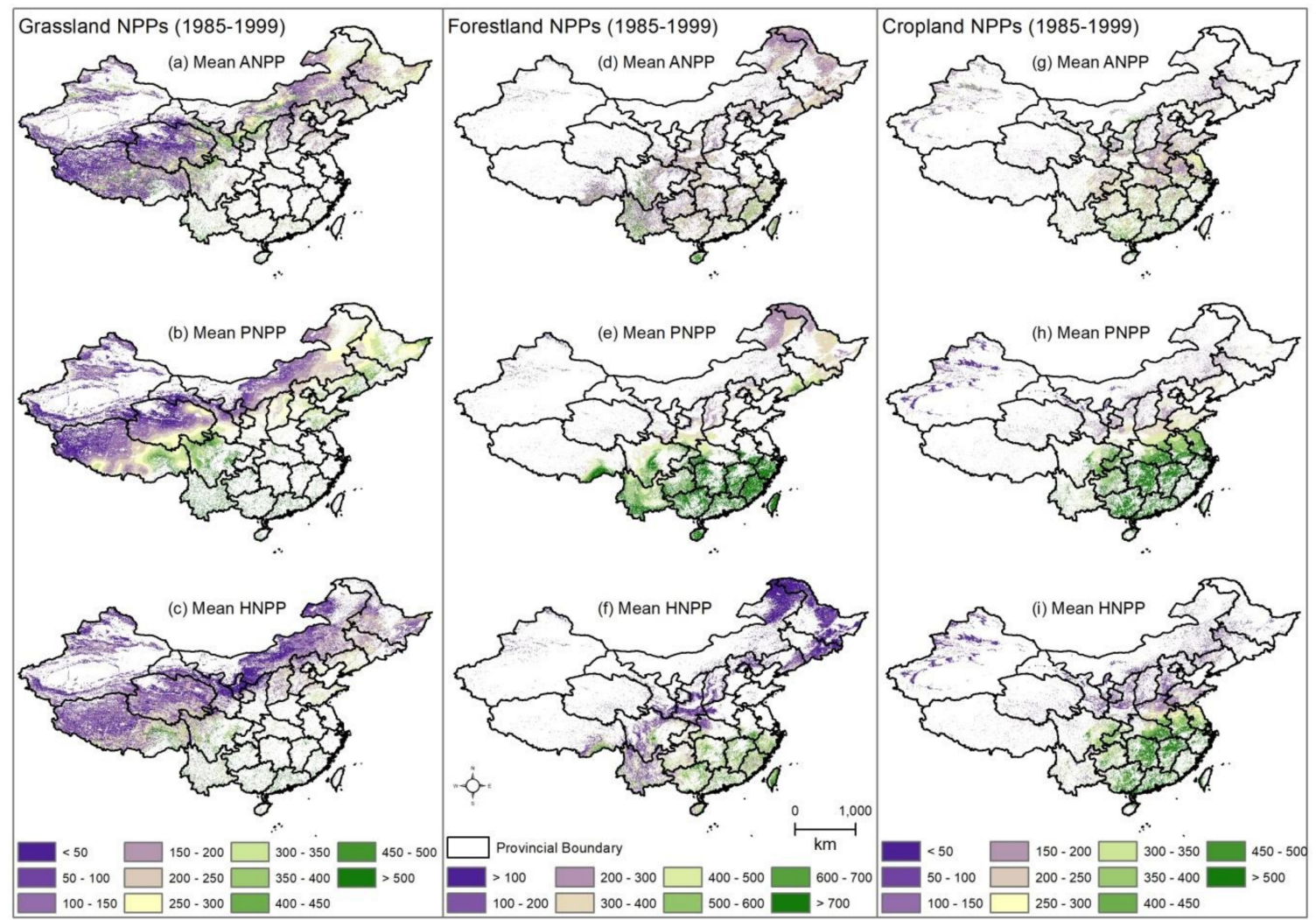

Figure 6. Mean actual net primary productivity (ANPP), mean potential NPP (PNPP), and mean human-induced NPP (HNPP) for the base period: (a-c) the mean ANPP, PNPP, and HNPP for grassland, respectively; (d-f) the mean ANPP, PNPP, and HNPP for forestland, respectively; (g-i) the mean ANPP, PNPP, and HNPP for cropland, respectively. 


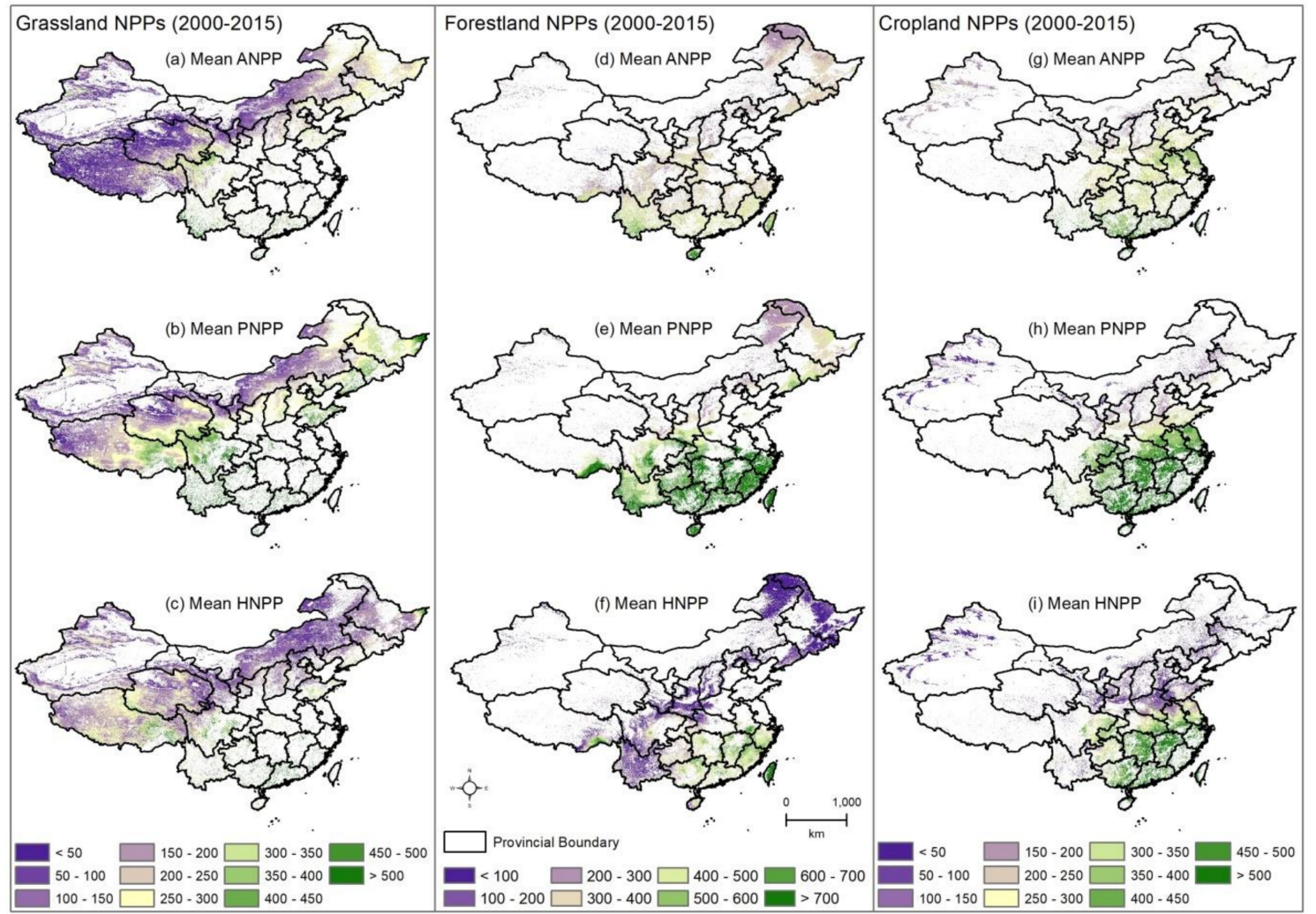

Figure 7. Mean actual NPP (ANPP), mean potential NPP (PNPP), and mean human-induced NPP (HNPP) for the restoration period: (a-c) are the mean ANPP, PNPP, and HNPP for grassland, respectively; $(\mathbf{d}-\mathbf{f})$ are the mean ANPP, PNPP, and HNPP for forestland, respectively; (g-i) are the mean ANPP, PNPP, and HNPP for cropland, respectively.

\subsubsection{Slopes of Climate Variables and NPP and Scenario Development}

The linear regression method was adopted to compute the spatial change patterns of vegetation productivity and climate variables. The time series of pixels were calculated to obtain the slope coefficients of a trend line using the following formula:

$$
\text { Slope }=\frac{n \times \sum_{i=1}^{n}\left(i \times \operatorname{Var}_{i}\right)-\left(\sum_{i=1}^{n} i\right)\left(\sum_{i=1}^{n} \operatorname{Var}_{i}\right)}{n \times\left(\sum_{i=1}^{n} i^{2}\right)-\left(\sum_{i=1}^{n} i\right)^{2}}
$$

An F-test was then applied to detect the statistical significance of spatial change patterns. The following formula was applied to test the significance of slopes calculated from the above equation:

$$
F=U \times\left(\frac{n-2}{Q}\right)
$$

where $\mathrm{U}$ and $\mathrm{Q}$ are the regression sum of squares and residual sum of squares, respectively; and $n$ is the total number of years.

The climate and human impacts on NPP change were investigated by comparing the slope of $\operatorname{ANPP}\left(\mathrm{S}_{\mathrm{A}}\right)$, slope of PNPP $\left(\mathrm{S}_{\mathrm{P}}\right)$, and slope of $\operatorname{HNPP}\left(\mathrm{S}_{\mathrm{H}}\right)$, as described in Table 2. 
Table 2. Scenarios developed to differentiate the relative contributions of human activities and climate variations in vegetation productivity change. Note: + indicates NPP increase and - refers to a decrease in NPP.

\begin{tabular}{|c|c|c|c|c|}
\hline Vegetation Status & $\mathrm{S}_{\mathrm{A}}$ & $S_{P}$ & $\mathrm{~S}_{\mathrm{H}}$ & Dominant Factor \\
\hline \multirow{4}{*}{ Increase } & + & + & + & Climate-Dominated Vegetation Restoration (CDR) \\
\hline & + & - & - & Human-Dominated Vegetation Restoration (HDR) \\
\hline & + & + & - & Both Dominated the Vegetation Restoration (BDR) \\
\hline & + & - & + & Neither Affected the Vegetation Restoration (Error) \\
\hline \multirow{4}{*}{ Decrease } & - & + & + & Human-Dominated Vegetation Degradation (HDD) \\
\hline & - & - & - & Climate-Dominated Vegetation Degradation (CDD) \\
\hline & - & - & + & Both Dominated the Vegetation Degradation (BDD) \\
\hline & - & + & - & Neither Affected the Vegetation Degradation (Error) \\
\hline
\end{tabular}

\subsubsection{Hurst Exponent}

The Hurst exponent $(\mathrm{H})$ was introduced by a British hydrologist in 1951 [57] and was modified in 1969 by Mandelbrots [58]. In recent studies, it was effectively applied to investigate the long term consistency of time-series data to predict future trends [59]. The following steps are involved in $\mathrm{H}$ value calculations:

- Divide the time series $\{\operatorname{NPP}(\tau)\}(\tau=1, \ldots, n)$ into sub-series $x(i)$, and for each sub-series $i=1$, $\ldots, \tau$.

- Then define the mean sequence of time series,

$$
\overline{\operatorname{NPP}}_{(\tau)}=\frac{1}{\tau} \sum_{i=1}^{\tau} x(i)
$$

- Compute the cumulative deviation of each NPP,

$$
x(i, \tau)=\sum_{i=1}^{i}\left(N P P_{(i)}-\overline{N P P}_{(\tau)}\right), 1 \leq i \leq \tau
$$

- $\quad$ Generate the range sequence $R(\tau)$,

$$
R(\tau)=\max _{1 \leq i \leq \tau} x(i, \tau)-\min _{1 \leq i \leq \tau}(i, \tau), \tau=1, \ldots, n
$$

- Then calculate the standard deviation sequence $S(\tau)$,

$$
S(\tau)=\sqrt{\frac{1}{\tau} \sum_{i=1}^{\tau}\left(N P P_{(i)}-\overline{N P P}_{(\tau)}\right)^{2}}, \tau=1,2 \ldots, n
$$

- At the end, rescale the calculated range,

$$
\frac{R(\tau)}{S(\tau)}=(C \tau)^{H}
$$

where, $\mathrm{H}$ is the Hurst exponent, and can be calculated by fitting the above equation as follows:

$$
\log \left(\frac{R}{S}\right)_{(n)}=a+(H \times \log (n))
$$


Literature indicates that the range of Hurst exponents varies from 0 to 1 , and is divided into three categories for future predictions [27,54]. If $H>0.5$, the trend NPP time series would be considered to be consistent with the study period. A value $H<0.5$ would indicate inconsistent behavior for NPP time series, whereas $H=0.5$ would mean the time series trend of NPP is absolutely random, with no consistency.

The degree of vegetation change and its consistency were evaluated based on spatial change trends of ANPP, its significance, and Hurst values (Figure 8). The eight possible scenarios were developed for vegetation sustainability assessment. The scenarios are described in Table 3.
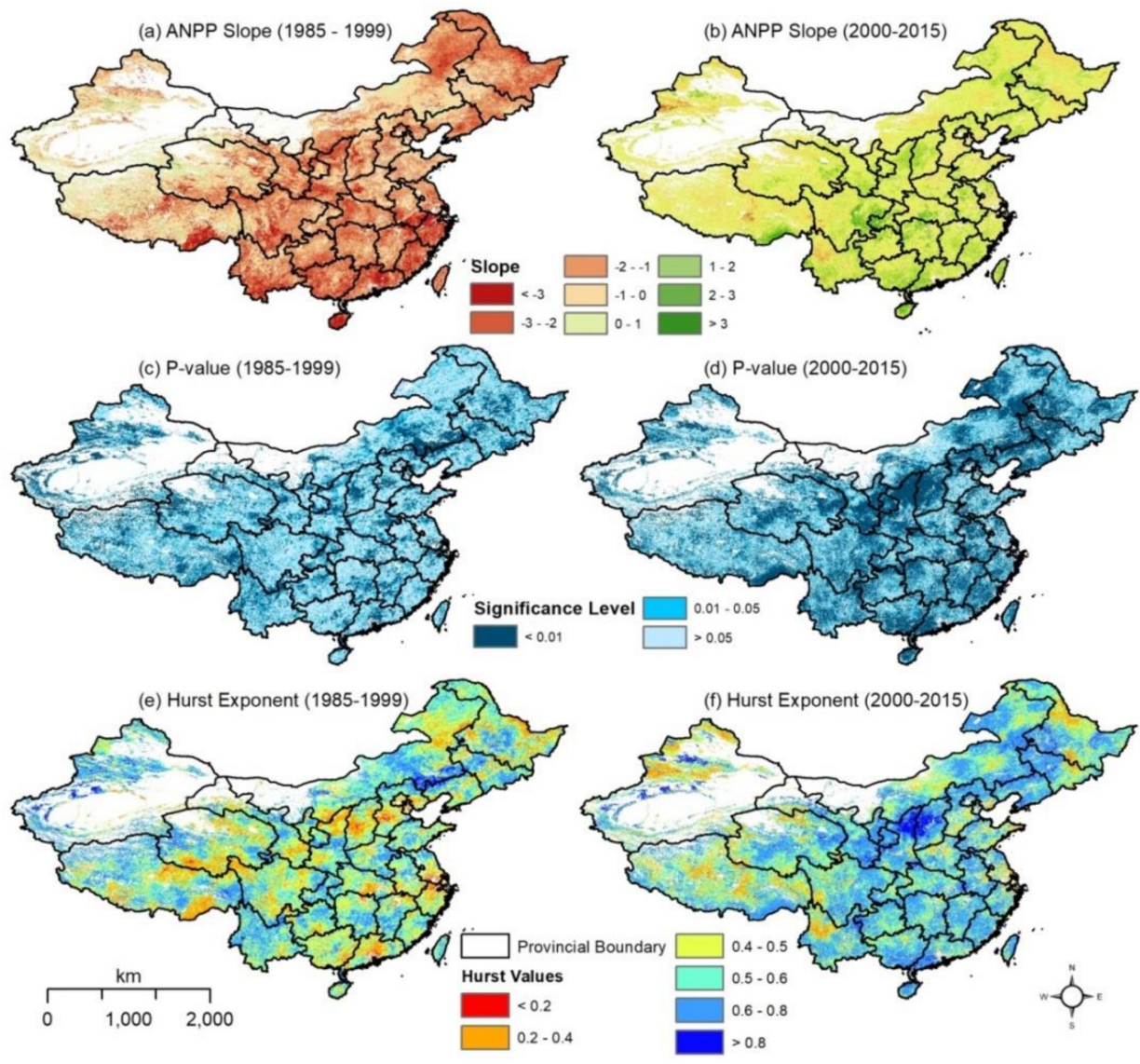

Figure 8. The material used to calculate the degree of ANPP change and its sustainability: $(\mathbf{a}, \mathbf{b})$ the slopes of base and restoration periods; (c,d) the P-values of ANPP for base and restoration periods; $(\mathbf{e}, \mathbf{f})$ calculated Hurst values for base and restoration periods.

Table 3. Scenarios for the degree of ANPP change and its consistency.

\begin{tabular}{cccc}
\hline ANPP Slope & P-Value & Hurst Exponent & Consistency and Degree of Vegetation Change \\
\hline+ & $<0.05$ & $>0.5$ & Consistent and Significant Restoration (CSR) \\
\hline+ & $>0.05$ & $>0.5$ & Consistent and Slight Restoration (CLR) \\
\hline+ & $<0.05$ & $<0.5$ & Inconsistent and Significant Restoration (ISR) \\
\hline+ & $>0.05$ & $<0.5$ & Inconsistent and Slight Restoration (ILR) \\
\hline- & $<0.05$ & $>0.5$ & Consistent and Significant Degradation (CSD) \\
\hline- & $>0.05$ & $>0.5$ & Consistent and Slight Degradation (CLD) \\
\hline- & $<0.05$ & $<0.5$ & Inconsistent and Significant Degradation (ISD) \\
\hline- & $>0.05$ & $<0.5$ & Inconsistent and Slight Degradation (ILD)
\end{tabular}




\subsubsection{Spatial Correlation Between Vegetation Productivity and Climate Factors}

The spatial patterns of Pearson's correlation coefficient between climate factors and ANPP were calculated to investigate the individual response of climate variations to ANPP change by using the following equation [60]:

$$
r_{x y}=\frac{n \times \sum_{i=1}^{n}\left(x_{i} \times y_{i}\right)-\sum_{i=1}^{n} x_{i} \sum_{i=1}^{n} y_{i}}{\sqrt{n \times \sum_{i=1}^{n} x_{i}^{2}-\left(\sum_{i=1}^{n} x_{i}\right)^{2}} \sqrt{n \times \sum_{i=1}^{n} y_{i}^{2}-\left(\sum_{i=1}^{n} y_{i}\right)^{2}}}
$$

The relationship of ANPP with precipitation $\left(\mathrm{P}_{\text {cor }}\right)$ and temperature $\left(\mathrm{T}_{\text {cor }}\right)$ was then assessed with areas of vegetation change due to climate variations to identify the dominant climatic factor. This assessment was done based on eight possible scenarios, which are expressed in Table 4 .

Table 4. Scenarios for the estimation of individual impacts of climate variables.

\begin{tabular}{cccc}
\hline Vegetation Status & $\mathbf{T}_{\text {cor }}$ & $\mathbf{P}_{\text {cor }}$ & Dominant Factor \\
\hline \multirow{3}{*}{ Increase } & + & - & Temperature-Dominated Vegetation Increase (TDI) \\
\cline { 2 - 4 } & - & + & Precipitation-Dominated Vegetation Increase (PDI) \\
\cline { 2 - 4 } & + & + & Both Dominated the Increase (BDI) \\
\hline \multirow{2}{*}{ Decrease } & - & - & Neither Affected the Vegetation Increase (NDI) \\
\cline { 2 - 4 } & + & + & Temperature-Dominated Vegetation Decrease (TDD) \\
\hline & - & - & Precipitation-Dominated Vegetation Decrease (PDD) \\
\hline & + & + & Neither Affected the Vegetation Decrease (NDD) \\
\hline
\end{tabular}

\section{Results}

\subsection{Drivers of Vegetation Dynamics}

Vegetation dynamics were investigated based on two driving forces: (1) climate variations and (2) human activities. Figure 9 indicates the spatial change patterns of three vegetation classes. Spatial patterns were developed based on eight scenarios, defined in Table 1. Figure 9 indicates the areas of NPP changes due to the individual contribution of climate variations and human activities and the combined effects of both factors, whereas the areas unaffected by these two driving forces are neglected. The overall pattern indicates an NPP decrease during the base period, and conversely increasing patterns can be seen during the restoration period. The spatial patterns of forest and agriculture classes for the base period and the restoration period are almost identical to each other; grassland shows variability in the results. To be precise, grassland restoration and degradation are observed during the base and restoration periods, respectively, driven by both climate variation and human activities. However, climate variation affected grassland ecosystems slightly more than human activities. 


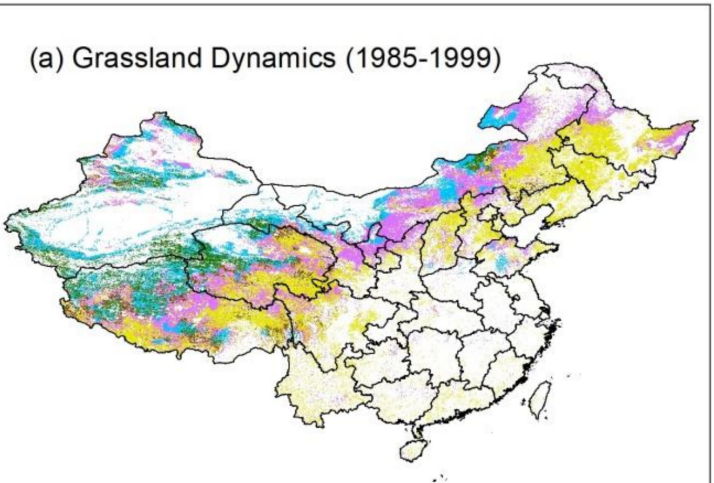

(b) Grassland Dynamics (2000-2015)

(c) Forest Dynamics (1985-1999)
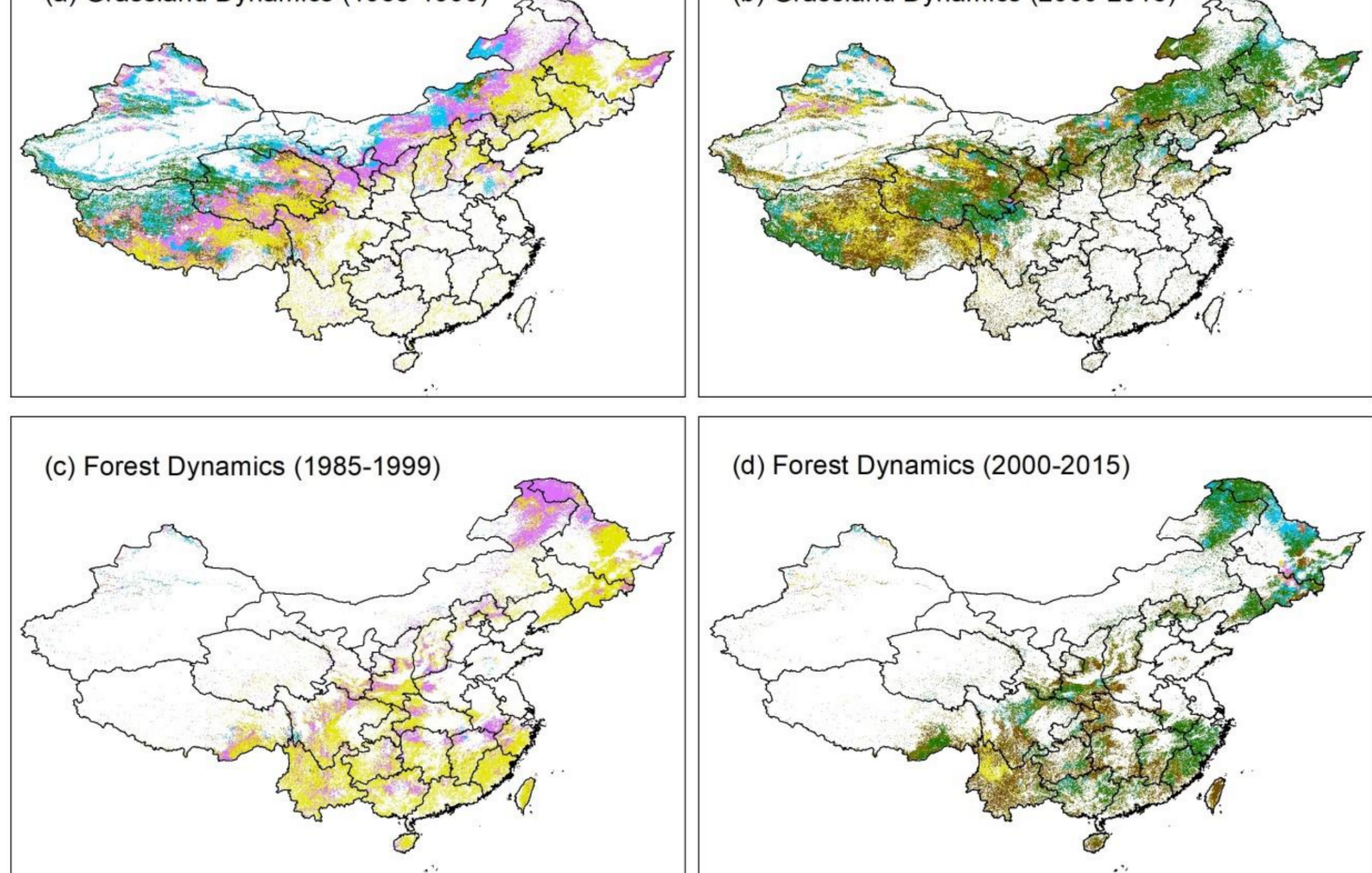

(d) Forest Dynamics (2000-2015)

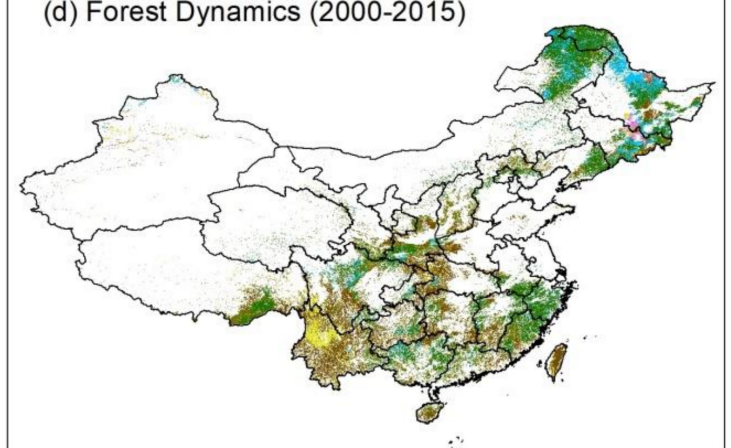

(e) Cropland Dynamics (1985-1999)

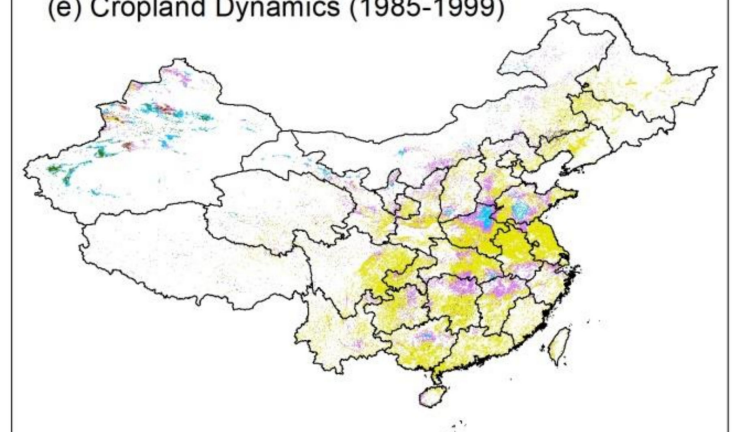

(f) Cropland Dynamics (2000-2015)
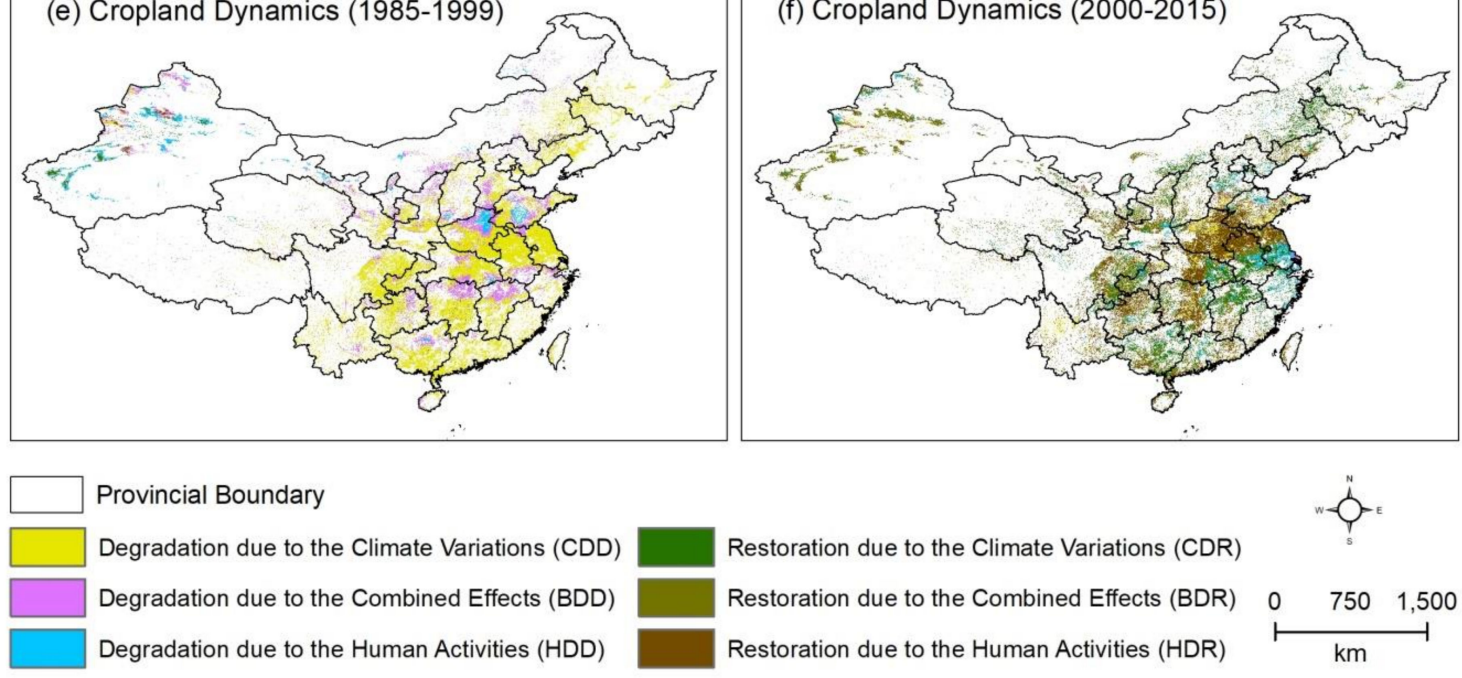

Provincial Boundary
Degradation due to the Climate Variations (CDD)
Degradation due to the Combined Effects (BDD)
Degradation due to the Human Activities (HDD)

Restoration due to the Climate Variations (CDR)

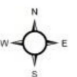

Restoration due to the Combined Effects (BDR)

Restoration due to the Human Activities (HDR)

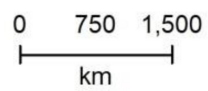

Figure 9. Spatial patterns of the relative contributions of climate variations and human activities: $(\mathbf{a}, \mathbf{b})$ the grassland NPP dynamics; (c,d) the forestland NPP dynamics; $(\mathbf{e}, \mathbf{f})$ the cropland NPP dynamics, under different scenarios for the base and restoration periods, respectively.

The results in Figure 10 illustrate that during the base period, there is no significant restoration, and only $9 \%$ of the total vegetation area reflects increasing trends. Grassland presents $8 \%$ of the total and $9 \%$ of the restored area, which is mainly driven by climate change, whereas the other two vegetation classes show only $1 \%$ restoration of the total vegetation area. In contrast, the restoration period indicates an increasing trend of over $78.7 \%$ of the total vegetation cover. Both driving forces contribute significantly to NPP restoration. However, climate variations affect a larger area than human activities for grassland and forests, while human activities affect the cropland restoration area slightly more than climate-driven NPP change. The restoration due to human activities was indeed the result of the successful implementation of ecological restoration and conservation programs. Figure 11 shows 
the NPP degradation patterns, where $91 \%$ of the total vegetation area during the base period shows decreasing trends, whereas $9 \%$ of the total vegetation area shows increasing trends. During the base period, the climate is found to be the dominant factor of vegetation degradation in comparison to human activities. Climate affects $52 \%$ of the total vegetation cover negatively. Human activities and the combined contribution of both factors are $11 \%$ and $28 \%$, respectively. The dominant negative climate contribution can be seen in all three classes. However, human activities also contribute to grassland degradation. The restoration period indicates that grassland degradation is mainly driven by climate variations, however the contribution of human activities cannot be ignored. Cropland and forest show slight degradation, and human activities and climate factors contribute almost equally to NPP decrease during the restoration period.

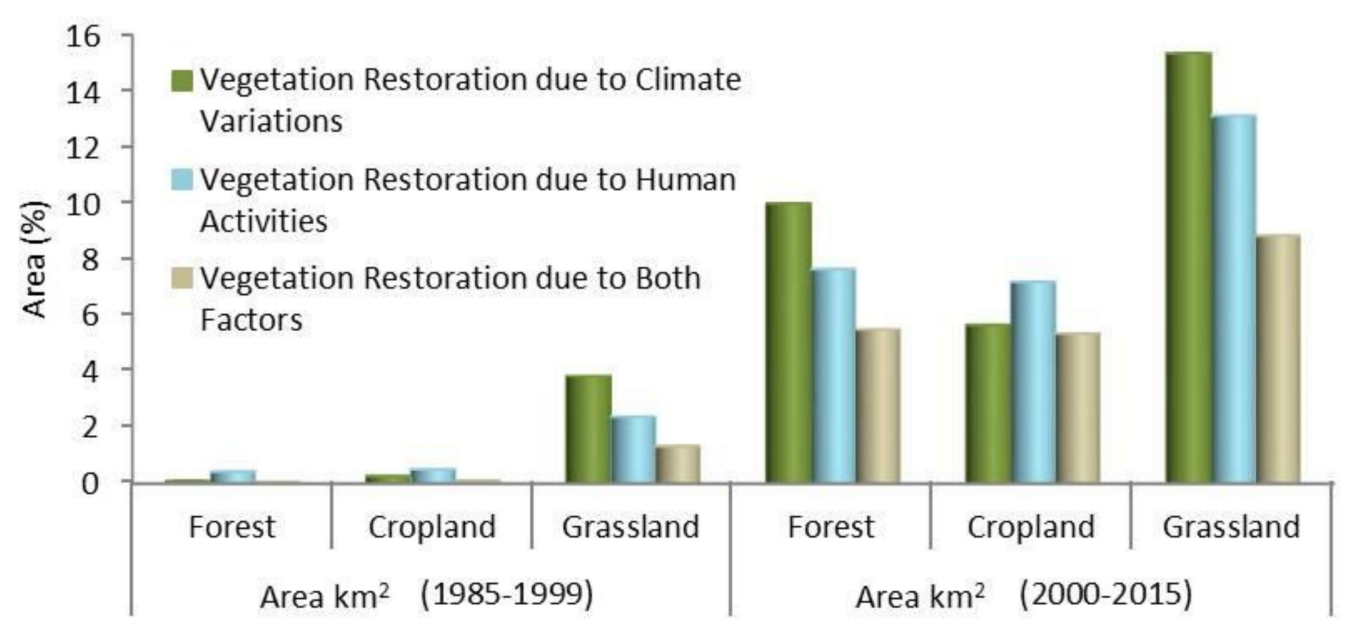

Figure 10. Relative contributions of climate and human activities for NPP restoration of three vegetation classes.

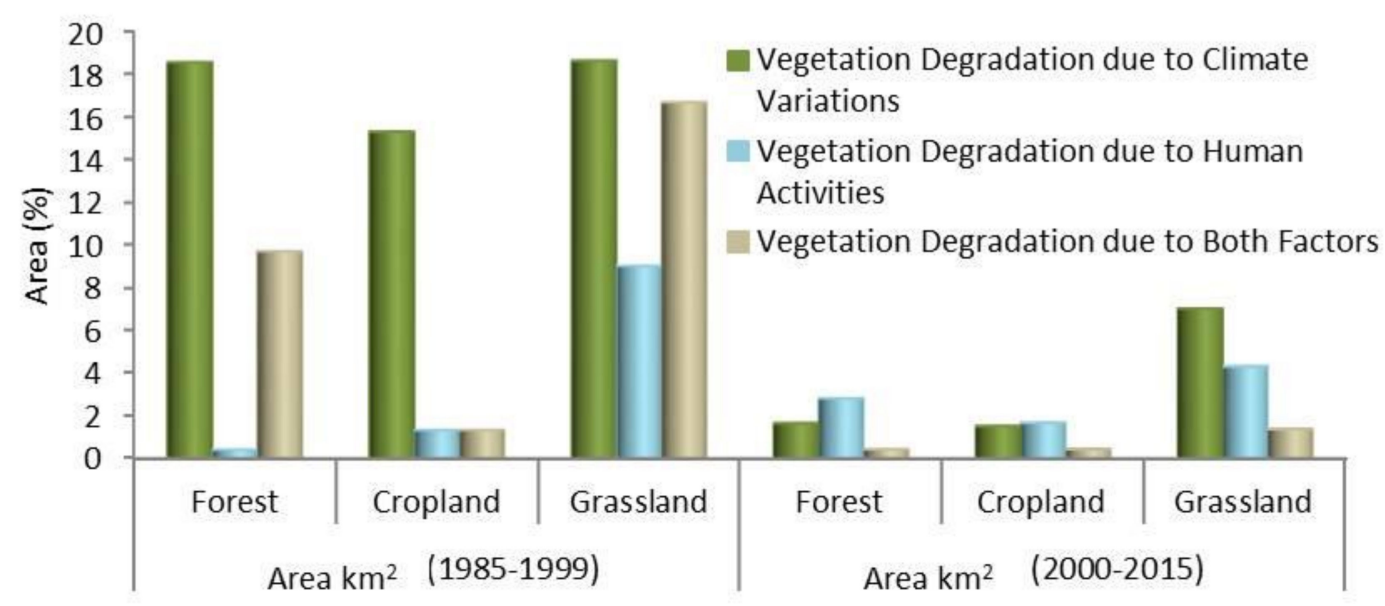

Figure 11. Relative contributions of climate and human activities for NPP degradation of three vegetation classes.

The quantitative measures of NPP dynamics for both driving forces are given in Table 5 . The combined effects of climate change and human activities are found to have more impact on quantitative changes of vegetation. For the restoration period, the combined effects of climate change and human activities contribute the highest amount of productivity per unit area in vegetation restoration $\left(1.11 \mathrm{gC} \mathrm{m}^{-2} \mathrm{yr}^{-1}\right)$ and degradation $\left(0.67 \mathrm{gC} \mathrm{m}^{-2} \mathrm{yr}^{-1}\right)$. Whereas, climate change contributes the lowest amount of productivity per unit area in vegetation restoration $\left(0.56 \mathrm{gC} \mathrm{m}^{-2} \mathrm{yr}^{-1}\right)$ and degradation $\left(0.29 \mathrm{gC} \mathrm{m}^{-2} \mathrm{yr}^{-1}\right)$. For the base period, again the combined effects of climate variations 
and human activities are the main contributors in vegetation productivity changes per unit area, with a combined restoration amount of $0.65 \mathrm{gC} \mathrm{m}^{-2} \mathrm{yr}^{-1}$ and degradation amount of $2.01 \mathrm{gC} \mathrm{m}^{-2} \mathrm{yr}^{-1}$. However, climate variations have a minimal impact on vegetation productivity restoration $(0.21 \mathrm{gC}$ $\left.\mathrm{m}^{-2} \mathrm{yr}^{-1}\right)$ and human activities contribute minimally $\left(0.72 \mathrm{gC} \mathrm{m}^{-2} \mathrm{yr}^{-1}\right)$ to decreasing the vegetation productivity per unit area, as described in Table 5.

Table 5. Statistics of the NPP dynamics for the base and restoration periods.

\begin{tabular}{|c|c|c|c|c|}
\hline \multirow[b]{2}{*}{$\begin{array}{c}\text { Drivers of NPP } \\
\text { Change }\end{array}$} & \multicolumn{2}{|c|}{ 2000-2015 } & \multicolumn{2}{|c|}{ 1985-1999 } \\
\hline & $\begin{array}{c}\text { Increase } \\
\left(\mathrm{gC} \mathrm{m}^{-2} \mathrm{yr}^{-1}\right)\end{array}$ & $\begin{array}{c}\text { Decrease } \\
\left(\mathrm{gC} \mathrm{m}^{-2} \mathrm{yr}^{-1}\right)\end{array}$ & $\begin{array}{c}\text { Increase } \\
\left(\mathrm{gC} \mathrm{m}^{-2} \mathrm{yr}^{-1}\right)\end{array}$ & $\begin{array}{c}\text { Decrease } \\
\left(\mathrm{gC} \mathrm{m}^{-2} \mathrm{yr}^{-1}\right)\end{array}$ \\
\hline Climate Variation & 0.56 & 0.29 & 0.21 & 1.41 \\
\hline Human Activities & 0.63 & 0.31 & 0.36 & 0.72 \\
\hline Both & 1.11 & 0.67 & 0.65 & 2.01 \\
\hline
\end{tabular}

It was challenging to quantitatively evaluate our results. Initially, we validated our results against land cover changes (such as plantation and deforestation) using the MODIS (MCD12Q1) product for 2001 and 2015. Then, six random pockets from the areas of significant changes after 1999 were selected and compared with high-resolution imagery of Google Earth for the same season, as shown in Figure 12. Pockets 1, 3, 4, 5, and 6 show vegetation restoration, whereas pocket 2 indicates vegetation degradation due to construction land in that area (Heilongjiang Province). Plantation is observed in pockets 1, 5, and 6 (areas of the Loess Plateau and Inner Mongolia), where our results indicate anthropogenic impact plays a dominant role (covers $89 \%$ area of these three pockets). Vegetation restoration is observed due to the combined effects of climate and human activities in pockets 3 and 4 (as some plantation patches are found in those areas). In pocket 2 , our results indicate that the anthropogenic impact also plays a dominant role (covers $97 \%$ area of pocket 2 ).
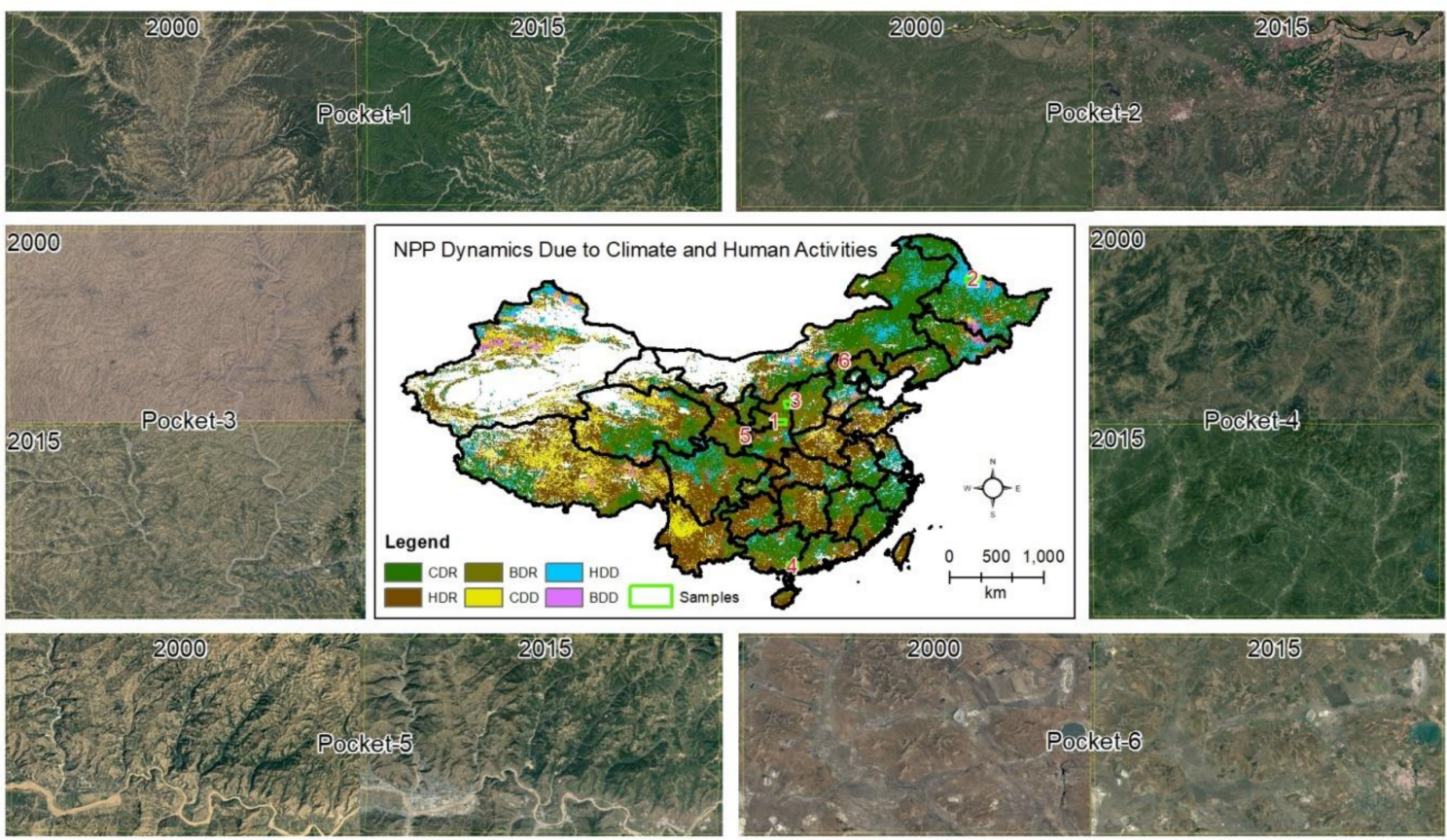

Figure 12. Vegetation changes during the restoration period in selected pockets, which verify the results illustrated in Figure 9.

Obvious vegetation changes are observed in the six randomly selected pockets. Additionally, the pockets selected from the areas of NPP restoration due to human activities show plantation in 
Google Earth images, whereas NPP degradation areas indicate replacement of vegetated areas into impervious surfaces.

\subsection{Vegetation Sustainability and Degree of Change}

Spatial patterns of vegetation sustainability and degree of change were determined as defined in Table 3. Spatial patterns (Figure 13) indicate that during the period from 1985 to 1999, an overall decrease is observed in all vegetation types. Individually describing the vegetation classes for the base period, it can be seen that only grassland restoration is found in Qinghai-Tibet, Xingjiang, and Inner Mongolia regions. In addition, forest and croplands do not show considerable restoration. Conversely, strong vegetation restoration patterns are observed from 2000 to 2015. All the vegetation classes increase either consistently or inconsistently. Grassland restoration is mainly found in the middle part of China, whereas forest and cropland restorations are observed in the middle, north-eastern, and southern regions of China. During the restoration period, some grassland degradation patches are observed across all of China. Similarly, forest and cropland degradation spots are also observed. However, those are not threatening under slight degradation conditions.

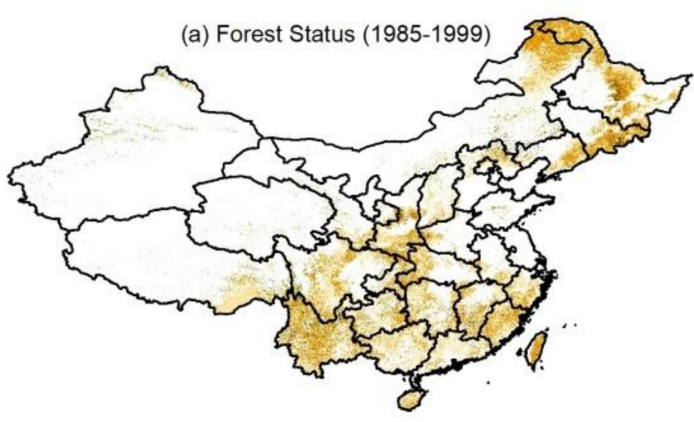

(c) Grassland Status (1985-1999)

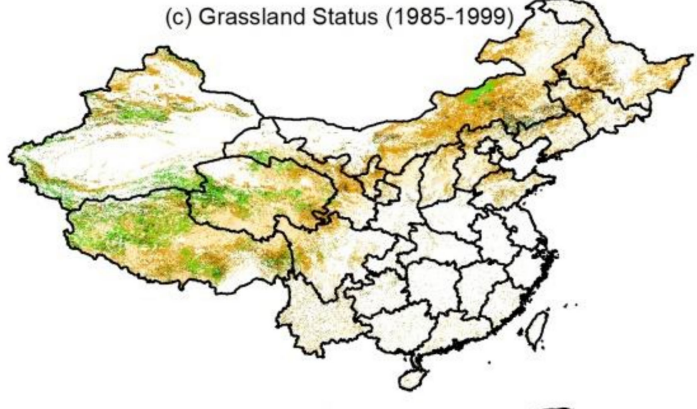

(e) Cropland Status (1985-1999)

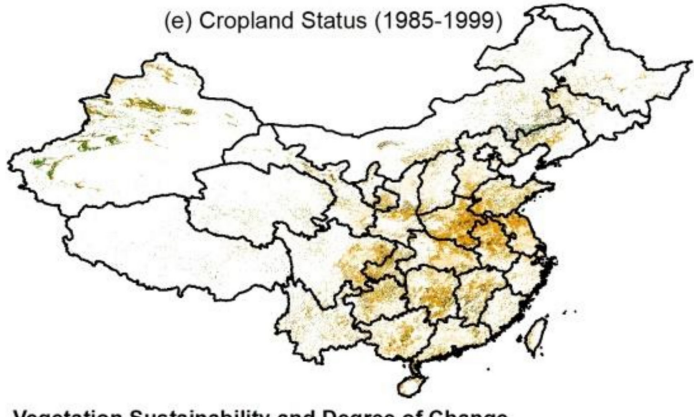

Vegetation Sustainability and Degree of Change
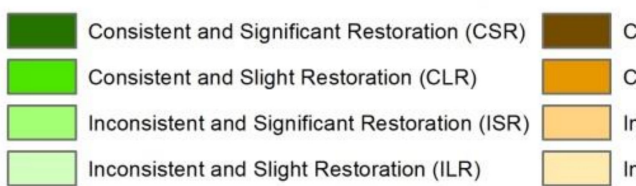

Consistent and Significant Degradation (CSD)

Consistent and Slight Degradation (CLD)

Inconsistent and Significant Degradation (ISD)

Inconsistent and Slight Degradation (ILD)

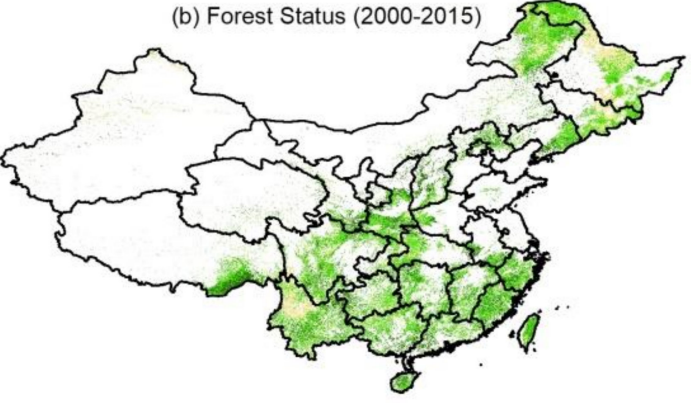

(d) Grassland Status (2000-2015)
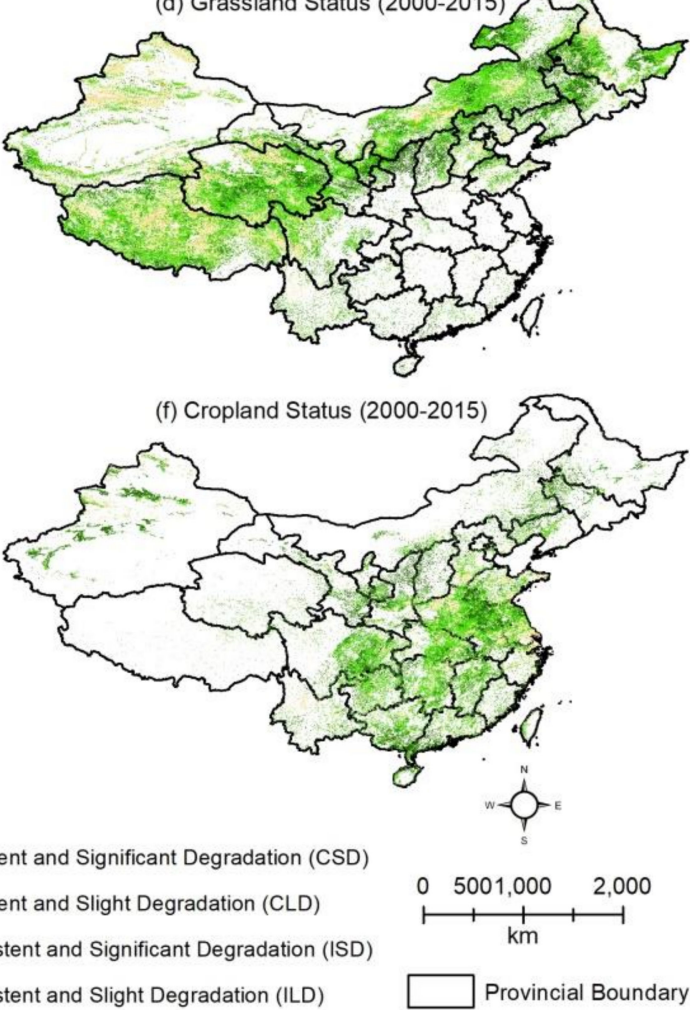

Figure 13. Spatial patterns of vegetation consistency and degree of change: $(\mathbf{a}, \mathbf{b})$ the spatial patterns of forestland NPP change; $(\mathbf{c}, \mathbf{d})$ the spatial patterns of grassland NPP change; $(\mathbf{e}, \mathbf{f})$ the spatial patterns of cropland NPP change for base and restoration periods, respectively. 
Figures 14 and 15 illustrate the statistics of vegetation dynamics under eight different scenarios. It can be seen from the graphs that a considerable decrease happens before 2000, and spatial patterns indicate both consistent and inconsistent behavior of vegetation degradation. The results of the base period show that the continuity of the same degradation patterns could have severely damaged the China's ecological resources. However, the successful implementation of the Grain for Green Program and other ecological restoration projects enormously restored the vegetation ecosystems of China, as indicated in the results for the restoration period. The patterns of the restoration period present consistent behavior. Approximately $30 \%$ of all vegetation classes show significant restoration, whereas over $40 \%$ show slight restoration. Thus, the results for both periods are almost opposite to each other.

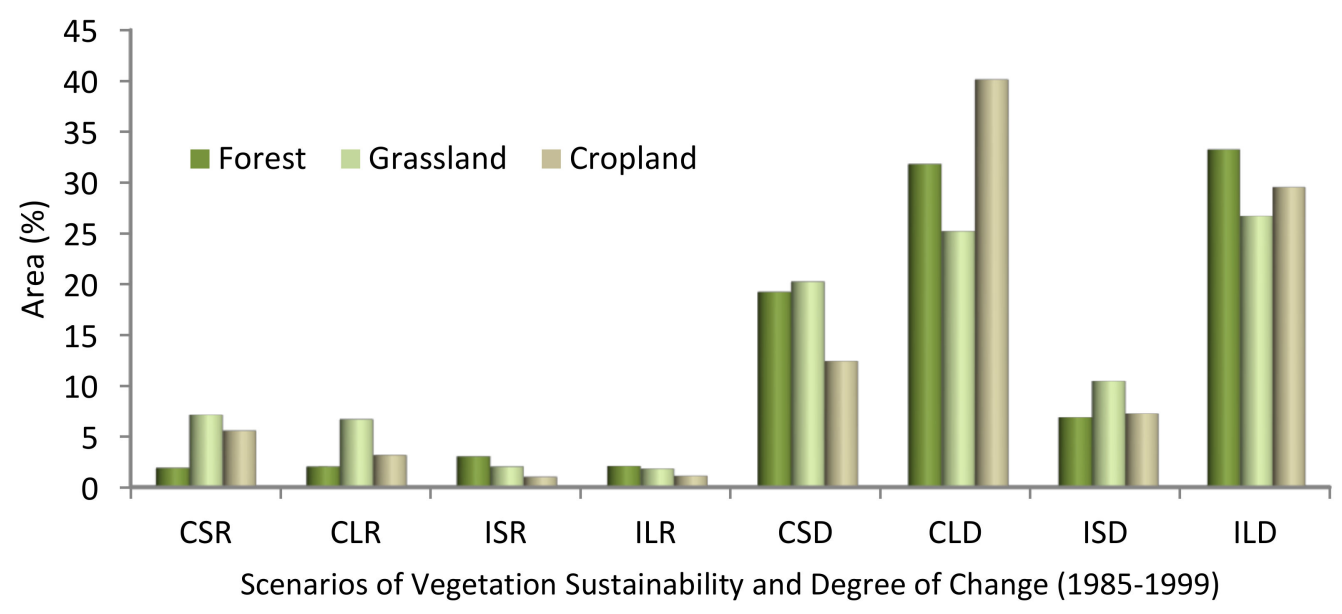

Figure 14. Sustainability and degree of NPP change under different scenarios for the base period.

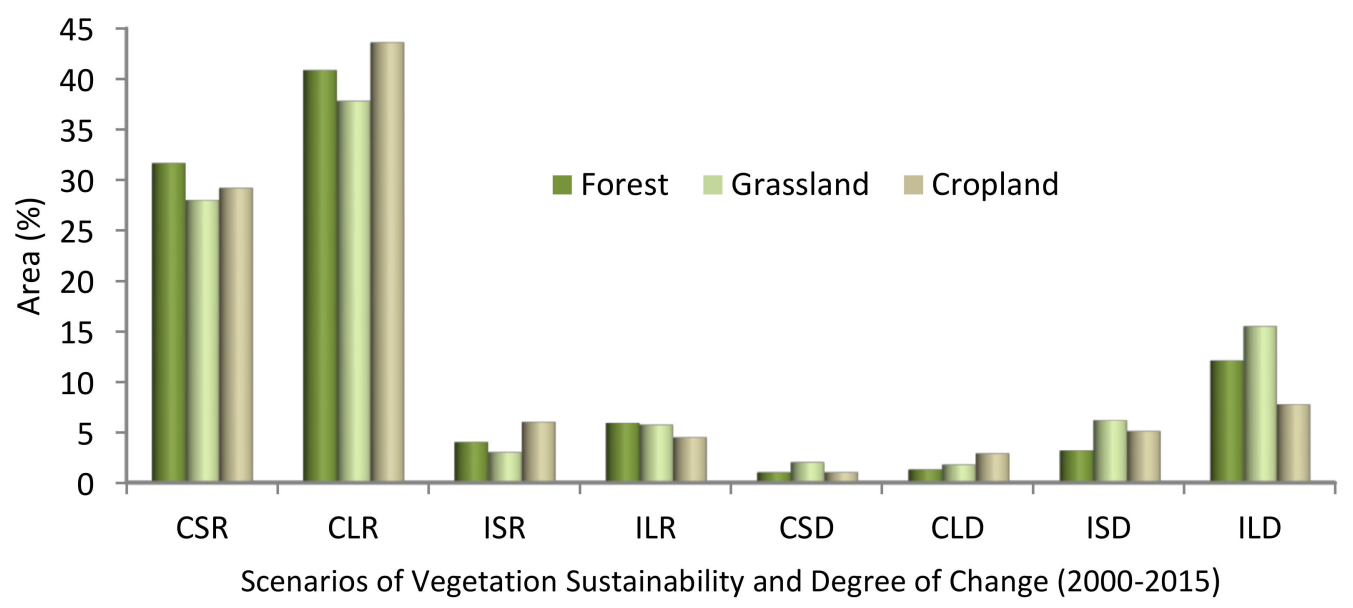

Figure 15. Sustainability and degree of NPP change under different scenarios for the restoration period.

\subsection{Individual Contributions of Climate Factors and Human Activities}

The individual contributions of climate factors on vegetation changes were investigated to quantify the most sensitive parameter to vegetation changes. For this purpose, pixel to pixel Pearson's correlation between ANPP and climatic factors was calculated and climate-dominated vegetation change areas (Figure 9) were compared based on the scenarios defined in Table 4.

Figures 16 and 17 indicate that precipitation is a more sensitive indicator of vegetation changes in comparison to temperature. Both factors contribute differently in different geographic locations. Another point to be noted is that approximately $40 \%$ of the base period is not affected by either climatic 
indicator, but NPP is changed due to climatic impact in those areas. This highlights the importance of the climatic factor, which has a significant impact on vegetation productivity changes.

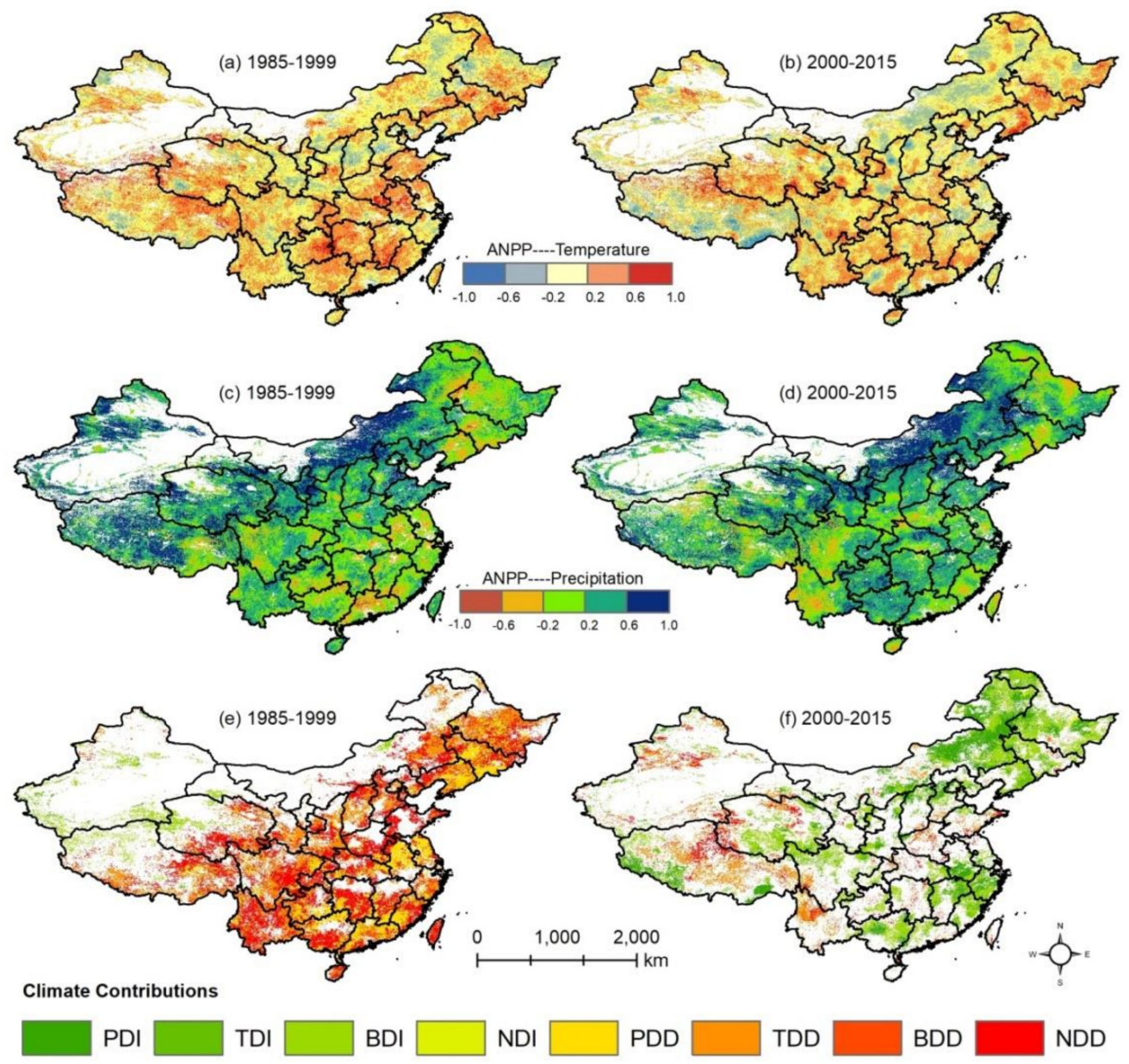

Figure 16. Correlation-based contributions of temperature and precipitation: $(\mathbf{a}, \mathbf{b})$ the correlations between ANPP and temperature; (c,d) the correlation between ANPP and precipitation; $(\mathbf{e}, \mathbf{f})$ the individual contributions of temperature and precipitation for the base and restoration periods, respectively.

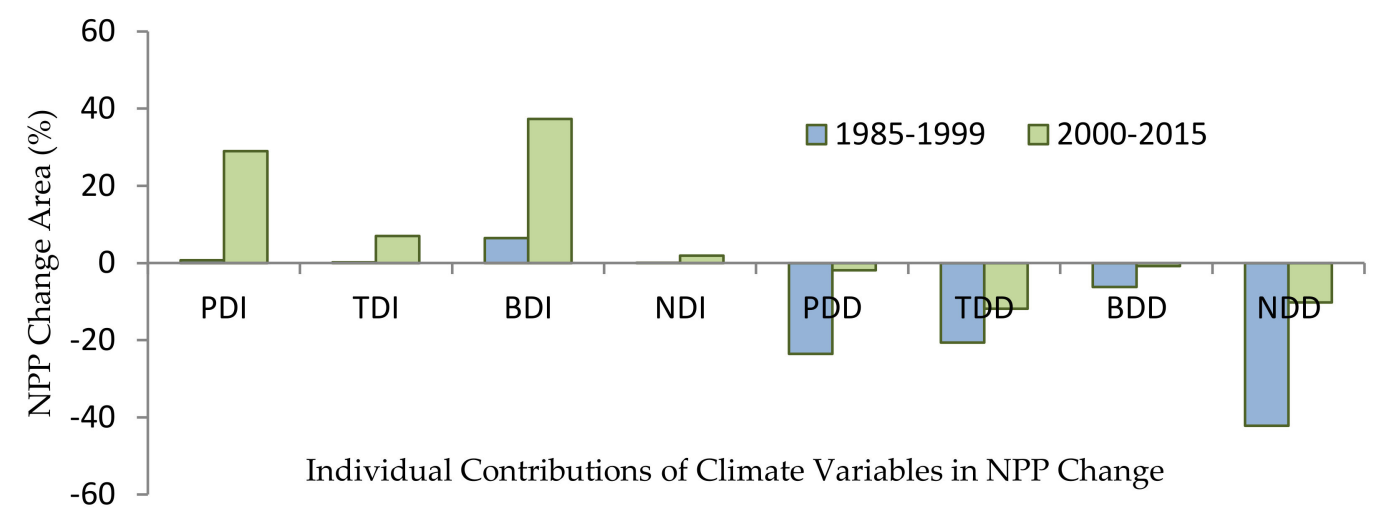

Figure 17. Individual contributions of climate variables in NPP change under different scenarios.

Precipitation-dominated increase (PDI) and both factors dominating the increase (BDI) are the prominent contributors in vegetation productivity increase during the restoration period, as illustrated in Figure 16. During the base period, both precipitation and temperature contributed equally 
in vegetation change; however, approximately $40 \%$ of the degraded area is controlled by an unknown climatic variable.

The human influence on vegetation dynamics was both positive and negative. It can be seen that factors such as rapid construction, economic revolution, and overgrazing contribute negatively, whereas proper landscape policies and plantation through ecological restoration and conservation programs contribute positively. This study uses the human influence datasets for the years 1993 and 2009. Due to the unavailability of temporal human footprint datasets at the yearly temporal resolution, 1993 data were used to analyze the NPP changes for the base period and 2009 data were applied to assess the NPP change at different human footprint pressure levels for the restoration period.

For this analysis, NPP dynamics due to human activities mapped in Figure 9 were incorporated with human footprint pressure data. Results for the base period (Table 6) indicate that human pressure does not have much effect on NPP restoration; however, NPP decreases in higher footprint regions. During the restoration period, higher footprint pressure led to both positive changes and negative changes (Table 6).

Table 6. Effect of human footprint pressure on NPP dynamics for the base and restoration periods.

\begin{tabular}{ccccc}
\hline & $\begin{array}{c}\text { NPP Dynamics from 1985-1999 } \\
\left(\mathbf{g C ~ m}^{-\mathbf{2}} \mathbf{y r}^{-\mathbf{1}}\right)\end{array}$ & $\begin{array}{c}\text { NPP Dynamics from 2000-2015 } \\
\left(\mathbf{g C ~ m}^{\mathbf{- 2}} \mathbf{y r}^{-\mathbf{1}}\right)\end{array}$ \\
\hline HFP & HDR & HDD & HDR & HDD \\
\hline$<5$ & 0.37 & -0.64 & 0.28 & -0.21 \\
\hline $5-10$ & 0.36 & -0.86 & 0.69 & -0.29 \\
\hline $10-15$ & 0.34 & -0.76 & 0.78 & -0.32 \\
\hline $15-20$ & 0.37 & -0.94 & 0.87 & -0.38 \\
\hline$>20$ & 0.40 & -0.93 & 0.85 & -0.51 \\
\hline
\end{tabular}

Figure 18 indicates NPP changes for three vegetation classes. An overall decrease and increase can be seen for all vegetation classes for the base and restoration periods, respectively. At different intensity levels of human footprints, the maximum NPP restoration is observed during the restoration period. When HFP crosses a threshold of 20, net NPP gain starts decreasing. This could be due to the highly populated areas (cities). For the base period, consistent behavior of NPP degradation is observed in the areas with HFP $>5$. 


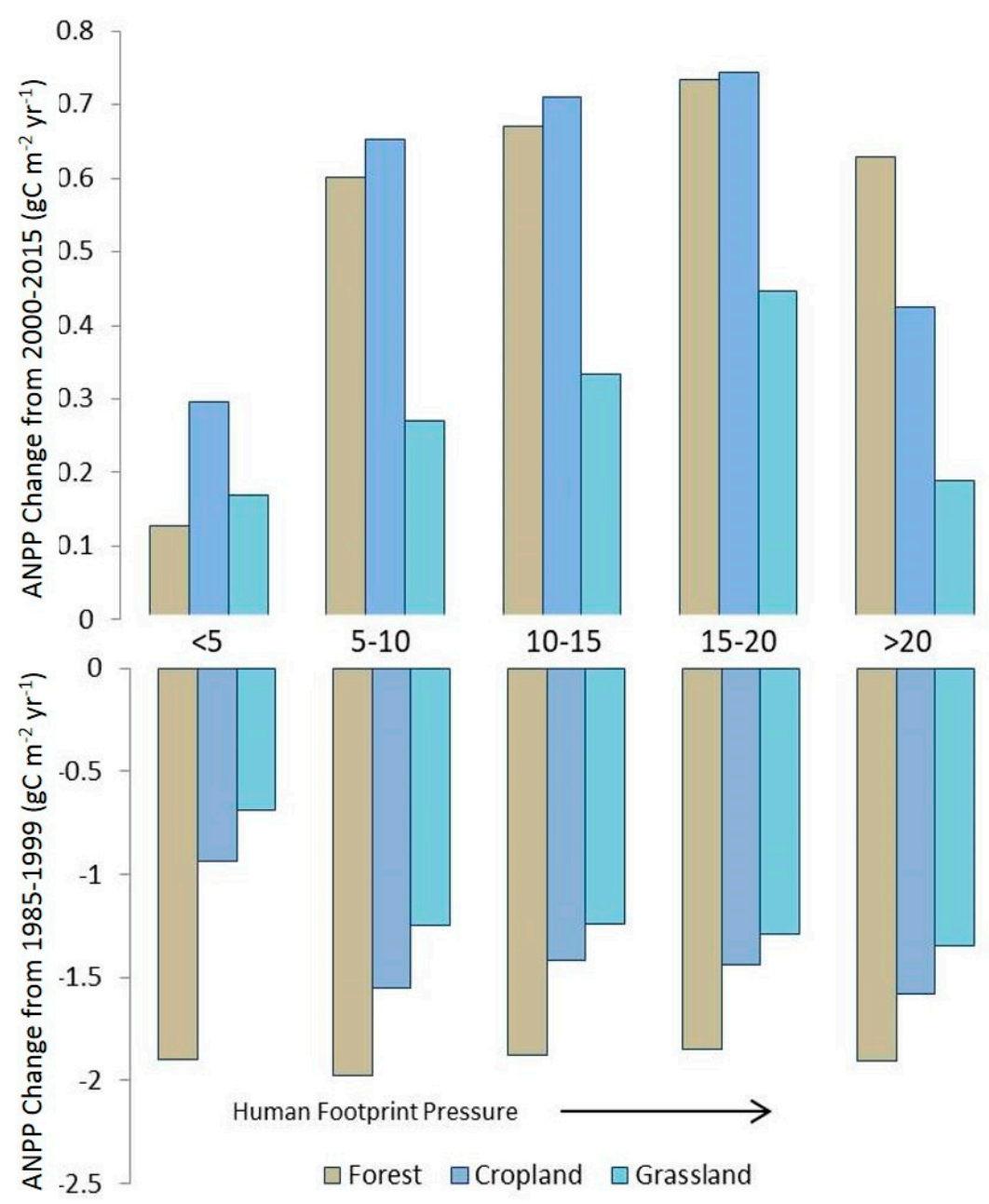

Figure 18. NPP change per unit area per year for the vegetation classes.

\section{Discussions}

Anthropogenic activities and climate fluctuations are the two dominant factors of changes in vegetation productivity. Several studies have already been conducted to distinguish the impact of these two factors on NPP dynamics by comparing ANPP, HNPP, and PNPP. However, most of them focused on grassland dynamics [36,61,62]. The Grain for Green Program was launched in 1999 in China, and since then a strong increase in grassland productivity has been observed [53]. Therefore, it is essential to quantify the impact of ecological restoration and conservation programs in China for all types of vegetation. The scenario simulation approach coupled with NPP is quite simple and is useful for differentiating the relative contributions of anthropogenic activities and climatic factors to vegetation productivity dynamics [57]. This approach enables accurate evaluation of the spatiotemporal variations in vegetation productivity driven by human activities and climate change [63]. Therefore, an NPP product (ChinaNPP_1985_2015) for China's terrestrial ecosystems was selected as an actual NPP measure for this study [47]. Precipitation- and temperature-based Thornthwaite memorial model were applied to simulate the potential NPP of vegetation classes. The Hurst exponent was applied to assess the consistency of vegetation spatial patterns, and a pixel-based Pearson's correlation was calculated to determine the individual impact of temperature and precipitation on NPP change.

The degree and sustainability of spatiotemporal NPP variations were determined by computing pixel values of the Hurst exponent, temporal change trends (slope), and significance level (p-value) of ANPP for both base and restoration periods. The study found an overall decreasing trend for the base period and an increasing trend for the restoration period, and grassland showed greater 
variability in comparison to other vegetation classes. Results (Figures 6-8) suggested that only grassland class represented a considerable portion ( $8 \%$ ) of the restored area during the base period, while $12 \%$ grassland degradation of the total vegetation area was found during the restoration period. Grassland productivity changes were mainly observed in Xinjiang, Qinghai-Tibet Plateau, and Inner Mongolia. Previous studies concluded that the grassland changes in Qinghai-Tibet plateau are mainly driven by climate change during both base and restoration periods [26,64]. Tian et al. [65] concluded that both climate and human factors contributed equally to vegetation restoration in Inner Mongolia after 1999. Similarly, Zhang et al. [35] found an overall increase in the grassland area of Xinjiang province. However, human activities (overgrazing) and climate factors contributed equally to vegetation degradation. Forests and cropland classes showed decreasing and increasing trends during base and restoration periods, respectively, in most areas of China.

As discussed earlier (see Section 3.1), vegetation productivity is primarily driven by anthropogenic activities and climate variations. NPP dynamics are generally influenced by two climatic factors: precipitation and temperature. Variations in temperature and precipitation affect the vegetation ecosystems by altering soil microbes and soil moisture, and by affecting the processes of plant respiration and photosynthesis. Consequently, these changes may control the productivity of vegetation ecosystem by regulating plant growth $[2,66]$. The results of this study suggest that climate change is an important factor in controlling grassland productivity (Figures 9-11 and Table 5), and several studies concluded that the contribution of climate change in vegetation dynamics is greater than human activities $[36,67,68]$. The outcomes of the current study partially agree with these conclusions. Our findings indicate that climate variations affect vegetation areas in China more than human factors, but contribute slightly lesser than anthropogenic factors in NPP change per unit area. Similarly, Liu et al. [69] studied grassland dynamics due to climate change and human activities from 2000 to 2013 and concluded that the relative contributions of climate and human activities for grassland dynamics of China were $41.45 \%$ and $45.22 \%$, respectively. In the current study, during the base period, climate change and human activities contributed approximately $43 \%$ and $22 \%$ to grassland dynamics, respectively, whereas $35 \%$ of the area was affected by both factors. However, during the restoration period, climate change and human activities contributed approximately $44 \%$ and $35 \%$ to grassland dynamics, respectively. However, $21 \%$ of the area was affected by both factors. Our statistics were different from the results of Liu et al. [69]; climate variations affected a larger area but quantitatively (NPP change per unit area) contributed less than human activities. Furthermore, Zhang et al. [35] studied the grassland dynamics of Xinjiang province and concluded that climate and human factors contributed equally to NPP decrease, whereas human activities played a relatively greater role in NPP restoration. Similarly, Tian et al. [65] studied vegetation dynamics of Inner Mongolia and found that both human and climate factors played almost equal roles in vegetation restoration. The results of this study also indicated that in dessert areas, climate affected 39\% of the area, human activities affected $37 \%$ of the area, and $24 \%$ of the vegetation area was affected by both factors. Therefore, the results are not very different from Tian et al. and Zhang et al. [35,65]. Similarly, Huang et al. [64] and Li et al. [26] concluded that the vegetation dynamics of Qinghai-Tibet plateau are primarily driven by climate variations, and precipitation is the leading climatic factor of vegetation growth. However, human activities had a negative impact on vegetation growth in most of the areas. On the other hand, the results partially agree with their conclusions, as the results indicate that vegetation productivity in Qinghai-Tibet plateau increased by $14.5 \%$, and $8.8 \%$ of the total vegetation area was decreased due to human activities.

The relative contributions of climate factors suggest that precipitation is the dominant factor in controlling NPP changes (Figures 16 and 17). We also observed consistency between precipitation, ANPP, and PNPP variations in most of the areas, suggesting that vegetation productivity in China is more sensitive to precipitation than temperature, which is similar to the conclusions of Yang et al. [36]. Chen et al. [70] indicated that water is a key factor of vegetation growth, and vegetation with a high root-to-shoot ratio and low leaf area index (LAI) may be ascribed to water shortage, which severely 
affects vegetation productivity [71-73]. The results of this study also coincide with Zhou et al. [3] and Zheng et al. [74], suggesting that wetter climates are more favorable for vegetation productivity growth [3,754. During the restoration period of the current study, the pixels with declining precipitation trends were mostly located in the areas with decreased ANPP (i.e., Xinjiang, Inner Mongolia, and Tibet regions). This means that the climate became drier in the areas with increased temperature, and NPP degradation due to climate variations can be expected in such regions (Figure 9). This observation can probably be explained as being due to warming, with a lower amount of precipitation leading to drought intensification [75]. Furthermore, some studies indicate that temperature increase can accelerate the photosynthesis process and carbon assimilation of plants. However, vegetation productivity is reduced when the temperature crosses an ecosystem threshold $[73,76]$, whereas the increasing trend of precipitation in Inner Mongolia is considered to be a dominant climatic factor for the restoration of vegetation productivity. In a similar context, Liang et al. [29] studied the climate response to spatiotemporal dynamics of ANPP in China and concluded that vegetation ANPP in arid and semi-arid regions is mainly controlled by precipitation, which is similar to the current study. In particular, our results suggest that climate-dominated NPP restoration is either controlled only by precipitation or by the combined effects of precipitation and temperature. Additionally, temperature-dominated areas showed an overall decrease in productivity.

Several studies state that human activities play a significant role in vegetation productivity changes $[2,36,77]$. The successful implementation of the Grain for Green Program has resulted in considerable vegetation development due to anthropogenic activities. The Grain for Green Program was launched in 1999 to change waste, barren, and grazing land into forest and grassland in fragile regions of the country [78]. Since then, vegetation degradation has been reduced, and improving patterns of vegetation productivity are reflected in our results and in other recent studies as well [3], providing evidence of successful implementation of this project. With the vegetation restoration programs, vegetation conservation programs also supported the NPP development after 1999. For example, GWP was introduced in 2003 to minimize the grazing pressure on grassland by employing cultivated pastures and by forbidding grazing [23]. In contrast to the base period, the results (Table 6) suggest that high human pressure leads to ANPP increase during the restoration period. This indicates that local communities play a major role in vegetation restoration and conservation after 1999, and these results are in line with Xu et. al. [34]. Moreover, Zhang et al. [35] observed that anthropogenic activities play a prominent part in grassland restoration of Xinjiang, particularly through grassland conservation programs. Similarly, Wang et al. [78] found that human activities restored NPP by 5923 gigagram carbon $(\mathrm{GgC})$ in the Tibet region. Xu et al. [23] showed that after implementation of the GWP, livestock numbers decreased by $7.8 \%$ in the Qinghai-Tibet Plateau, indicating a positive aspect of decreasing the grazing pressures. Similarly, Mu et al. [79] suggested that overall vegetation productivity improved in Inner Mongolia after the successful implementation of vegetation restoration and conservation programs. However, grazing pressure has not yet been reduced effectively, which could lead to vegetation degradation in the future [79]. This may be the reason for the NPP decrease in some areas of Inner Mongolia that is indicated in the current study.

There are some methodological shortcomings and data limitations of this study, which may be improved in the future. The human and climate factors are mainly responsible for NPP dynamics and trends. However, the HNPP (PNPP-ANPP) represents not only the anthropogenic activities, but also other factors, such as forest fires, vegetation species, and vegetation disease outbreaks. The influences of some factors may play a noticeable role in influencing NPP trends in some parts of China, and require quantitative analysis in the future, although temperature and precipitation are the dominant climate controlling factors (Figure 16) for vegetation productivity changes. Other factors may also be important for NPP variations. Some studies suggest that solar radiation also affects vegetation trends [25,59]. This should also be considered in the future, especially with grazing data, to account for the maximum possible impact factors. The applied assumptions in this study may lead to certain. However, this 
assessment, which considers all vegetation types in China for the base and restoration periods, may provide necessary guidelines for forest, grassland, and agricultural management activities.

\section{Conclusions}

This study was conducted to quantify the impact of the "Grain and Green Program" introduced in 1999 for the restoration of the green infrastructure of China. In response, we assessed the degree of NPP change and its consistency to investigate the future scenarios, the contributions of anthropogenic and climate factors to NPP variations, as well as the individual contributions of climate indicators and human influence. Our results show a strong improvement in NPP per unit area for all types of vegetation, including forestland, grassland, and croplands, after 1999. Based on the findings of this study, we conclude the following:

- Overall, the restoration period demonstrates increasing NPP trends for $78.7 \%$ and decreasing trends for $21.3 \%$ of the total vegetation cover, whereas the base period shows noticeable degradation in $91 \%$ and slight improvement in $9 \%$ of the total vegetation area.

- The consistently and significantly increasing NPP trends cover $29.64 \%$ of the total vegetation cover during the restoration period. Conversely, consistent and significant decreasing NPP trends are observed in $17.26 \%$ of the total vegetation cover during the restoration period.

- Both climatic factors and human activities contribute significantly to vegetation productivity changes. However, in this study, climate variations influence NPP changes in vegetation areas more than human activities.

- The quantitative contribution of climate to NPP restoration is found to be 0.21 and $0.56 \mathrm{gC} \mathrm{m}^{-2} \mathrm{yr}^{-1}$ during the base and restoration periods, respectively, whereas the quantitative contribution of climate to NPP degradation is found to be 2.41 and $0.29 \mathrm{gC} \mathrm{m}^{-2} \mathrm{yr}^{-1}$ during the base and restoration periods, respectively.

- The quantitative contribution of human activities to NPP restoration is found to be 0.36 and $0.63 \mathrm{gC} \mathrm{m}^{-2} \mathrm{yr}^{-1}$ during the base and restoration periods, respectively, while the quantitative contribution of human activities to NPP degradation is calculated to be 0.72 and $0.31 \mathrm{gC} \mathrm{m}^{-2} \mathrm{yr}^{-1}$ during the base and restoration periods, respectively.

- The combined effects of climate and human activities help to restore the maximum quantity of NPP $\left(0.65 \mathrm{gC} \mathrm{m}^{-2} \mathrm{yr}^{-1}\right)$ during the base period and during the restoration period $\left(1.11 \mathrm{gC} \mathrm{m}^{-2} \mathrm{yr}^{-1}\right)$.

- Precipitation seems to be a dominant factor in controlling NPP changes, whereas human footprint pressure has a positive impact on NPP changes for the restoration period and a negative impact on NPP changes for the base period.

Furthermore, grassland shows more variability during both base and restoration periods than cropland and forestland. The major grassland changes are observed in the areas of Qinghai-Tibet Plateau, Xinjiang, and Inner Mongolia. Some deforestation is observed in north-eastern and south-eastern parts of China during the restoration period. Our results may provide necessary guidelines and facilitate policy-makers in the management forest, grassland, and agricultural activities.

Author Contributions: S.N. and Y.Z. developed the idea for this study. Y.Z. supervised and S.N. executed the research plan. F.M.Q. and J.T. were involved in various discussions, while A.L. and P.K.P. provided technical support. All authors have read and agreed to the published version of the manuscript.

Funding: This research was funded by CAS Pioneer Hundred Talents Program and the National Natural Science Foundation of China (Grant No. 41971032).

Acknowledgments: This study was supported by CAS Pioneer Hundred Talents Program and the National Natural Science Foundation of China (Grant No. 41971032). The authors acknowledge Prof. Sun Rui from Beijing Normal University, China, for sharing the NPP field measurements. We appreciate the constructive suggestions from anonymous reviewers.

Conflicts of Interest: The authors declare no conflict of interest. 


\section{References}

1. Haberl, H.; Erb, K.H.; Krausmann, F.; Gaube, V.; Bondeau, A.; Plutzar, C.; Gingrich, S.; Lucht, W.; Fischer-Kowalski, M. Quantifying and mapping the human appropriation of net primary production in earth's terrestrial ecosystems. Proc. Natl. Acad. Sci. USA 2007, 104, 12942-12947. [CrossRef]

2. He, C.; Tian, J.; Gao, B.; Zhao, Y. Differentiating climate- and human-induced drivers of grassland degradation in the Liao River Basin, China. Environ. Monit. Assess. 2014, 187, 4199. [CrossRef]

3. Zhou, W.; Yang, H.; Huang, L.; Chen, C.; Lin, X.; Hu, Z.; Li, J. Grassland degradation remote sensing monitoring and driving factors quantitative assessment in China from 1982 to 2010. Ecol. Indic. 2017, 83, 303-313. [CrossRef]

4. Chen, B.; Zhang, X.; Tao, J.; Wu, J.; Wang, J.; Shi, P.; Zhang, Y.-J.; Yu, C. The impact of climate change and anthropogenic activities on alpine grassland over the Qinghai-Tibet Plateau. Agric. For. Meteorol. 2014, 189, 11-18. [CrossRef]

5. Li, A.; Wu, J.; Huang, J.-H. Distinguishing between human-induced and climate-driven vegetation changes: A critical application of RESTREND in inner Mongolia. Landsc. Ecol. 2012, 27, 969-982. [CrossRef]

6. Wessels, K.; Prince, S.; Malherbe, J.; Small, J.; Frost, P.; Vanzyl, D. Can human-induced land degradation be distinguished from the effects of rainfall variability? A case study in South Africa. J. Arid Environ. 2007, 68, 271-297. [CrossRef]

7. Ciais, P.; Reichstein, M.; Viovy, N.; Granier, A.; Ogée, J.; Allard, V.; Aubinet, M.; Buchmann, N.; Bernhofer, C.; Carrara, A.; et al. Europe-wide reduction in primary productivity caused by the heat and drought in 2003. Nature 2005, 437, 529-533. [CrossRef] [PubMed]

8. Newbold, T.; Hudson, L.; Hill, S.L.L.; Contu, S.; Lysenko, I.; Senior, R.; Börger, L.; Bennett, D.J.; Choimes, A.; Collen, B.; et al. Global effects of land use on local terrestrial biodiversity. Nature 2015, 520, 45-50. [CrossRef]

9. Herrmann, S.; Anyamba, A.; Tucker, C. Recent trends in vegetation dynamics in the African Sahel and their relationship to climate. Glob. Environ. Chang. 2005, 15, 394-404. [CrossRef]

10. Hua, W.; Chen, H.; Zhou, L.; Xie, Z.; Qin, M.; Li, X.; Ma, H.; Huang, Q.; Sun, S. Observational Quantification of Climatic and Human Influences on Vegetation Greening in China. Remote Sens. 2017, 9, 425. [CrossRef]

11. Brown, P.; Ming, Y.; Li, W.; Hill, S. Change in the magnitude and mechanisms of global temperature variability with warming. Nat. Clim. Chang. 2017, 7, 743-748. [CrossRef] [PubMed]

12. Huang, J.; Yu, H.; Dai, A.; Wei, Y.; Kang, L. Drylands face potential threat under $2{ }^{\circ} \mathrm{C}$ global warming target. Nat. Clim. Chang. 2017, 7, 417-422. [CrossRef]

13. Jiang, L.; Bao, A.; Guo, H.; Ndayisaba, F. Guli.jiapaer Vegetation dynamics and responses to climate change and human activities in Central Asia. Sci. Total. Environ. 2017, 599, 967-980. [CrossRef] [PubMed]

14. Piao, S.; Mohammat, A.; Fang, J.; Cai, Q.; Feng, J. NDVI-based increase in growth of temperate grasslands and its responses to climate changes in China. Glob. Environ. Chang. 2006, 16, 340-348. [CrossRef]

15. Suzuki, R.; Masuda, K.; Dye, D.G. Interannual covariability between actual evapotranspiration and PAL and GIMMS NDVIs of northern Asia. Remote Sens. Environ. 2007, 106, 387-398. [CrossRef]

16. Zhang, Y.; Zhang, C.; Wang, Z.; Chen, Y.; Gang, C.; An, R.; Li, J. Vegetation dynamics and its driving forces from climate change and human activities in the Three-River Source Region, China from 1982 to 2012. Sci. Total Environ. 2016, 563, 210-220. [CrossRef]

17. Zhang, Y.; Peng, C.; Li, W.-Z.; Tian, L.; Zhu, Q.; Chen, H.; Fang, X.; Zhang, G.; Liu, G.; Mu, X.; et al. Multiple afforestation programs accelerate the greenness in the 'Three North' region of China from 1982 to 2013. Ecol. Indic. 2016, 61, 404-412. [CrossRef]

18. Zhang, B.; He, C.; Burnham, M.; Zhang, L. Evaluating the coupling effects of climate aridity and vegetation restoration on soil erosion over the Loess Plateau in China. Sci. Total Environ. 2016, 539, 436-449. [CrossRef]

19. Ding, C. Land policy reform in China: Assessment and prospects. Land Use Policy 2003, 20, 109-120. [CrossRef]

20. Wang, F.; Pan, X.; Wang, N.; Shen, C.; Lu, Q. Combating desertification in China: Past, present and future. Land Use Policy 2013, 31, 311-313. [CrossRef]

21. Song, W.; Deng, X.; Liu, B.; Li, Z.; Jin, G. Impacts of grain-for-green and grain-forblue policies on valued ecosystem services in Shandong Province, China. Adv. Meteorol. 2015, 2015, 213534. [CrossRef]

22. Wang, J.; Chen, Y.; Shao, X.; Zhang, Y.; Cao, Y. Land-use changes and policy dimension driving forces in China: Present, trend and future. Land Use Policy 2012, 29, 737-749. [CrossRef] 
23. Xu, H.-J.; Wang, X.-P.; Zhang, X.-X. Alpine grasslands response to climatic factors and anthropogenic activities on the Tibetan Plateau from 2000 to 2012. Ecol. Eng. 2016, 92, 251-259. [CrossRef]

24. Yao, R.; Wang, L.; Huang, X.; Chen, J.; Li, J.; Niu, Z. Less sensitive of urban surface to climate variability than rural in Northern China. Sci. Total Environ. 2018, 628, 650-660. [CrossRef]

25. Tong, X.; Wang, K.; Yue, Y.; Brandt, M.; Liu, B.; Zhang, C.; Liao, C.; Fensholt, R. Quantifying the effectiveness of ecological restoration projects on long-term vegetation dynamics in the karst regions of Southwest China. Int. J. Appl. Earth Obs. Geoinf. 2017, 54, 105-113. [CrossRef]

26. Li, L.; Zhang, Y.; Liu, L.; Wu, J.; Wang, Z.; Li, S.; Zhang, H.; Zu, J.; Ding, M.; Paudel, B. Spatiotemporal patterns of vegetation greenness change and associated climatic and anthropogenic drivers on the Tibetan Plateau during 2000-2015. Remote Sens. 2018, 10, 1525. [CrossRef]

27. Li, Q.; Zhang, C.; Shen, Y.; Jia, W.; Li, J. Quantitative assessment of the relative roles of climate change and human activities in desertification processes on the Qinghai-Tibet Plateau based on net primary productivity. Catena 2016, 147, 789-796. [CrossRef]

28. Wessels, K.; Prince, S.; Reshef, I. Mapping land degradation by comparison of vegetation production to spatially derived estimates of potential production. J. Arid Environ. 2008, 72, 1940-1949. [CrossRef]

29. Liang, W.; Yang, Y.; Fan, N.; Guan, H.; Zhang, T.; Long, D.; Zhou, Y.; Bai, D. Analysis of spatial and temporal patterns of net primary production and their climate controls in China from 1982 to 2010. Agric. For. Meteorol. 2015, 204, 22-36. [CrossRef]

30. Chen, D.; Lan, Z.; Hu, S.; Bai, Y. Effects of nitrogen enrichment on belowground communities in grassland: Relative role of soil nitrogen availability vs. soil acidification. Soil Biol. Biochem. 2015, 89, 99-108. [CrossRef]

31. Potter, C.; Klooster, S.; Genovese, V. Net primary production of terrestrial ecosystems from 2000 to 2009. Clim. Chang. 2012, 115, 365-378. [CrossRef]

32. Ugbaje, S.U.; Odeh, I.O.A.; Bishop, T.F.A.; Li, J. Assessing the spatio-temporal variability of vegetation productivity in Africa: Quantifying the relative roles of climate variability and human activities. Int. J. Digit. Earth 2016, 10, 879-900. [CrossRef]

33. Feng, Y.; Wu, J.; Zhang, J.; Zhang, X.; Song, C. Identifying the Relative Contributions of Climate and Grazing to Both Direction and Magnitude of Alpine Grassland Productivity Dynamics from 1993 to 2011 on the Northern Tibetan Plateau. Remote Sens. 2017, 9, 136. [CrossRef]

34. Xu, H.-J.; Wang, X.-P.; Zhang, X.-X. Impacts of climate change and human activities on the aboveground production in alpine grasslands: A case study of the source region of the Yellow River, China. Arab. J. Geosci. 2017, 10, 17. [CrossRef]

35. Zhang, R.; Liang, T.; Guo, J.; Xie, H.; Feng, Q.; Aimaiti, Y. Grassland dynamics in response to climate change and human activities in Xinjiang from 2000 to 2014. Sci. Rep. 2018, 8, 2888. [CrossRef]

36. Yang, Y.; Wang, Z.; Li, J.; Gang, C.; Zhang, Y.; Zhang, Y.; Odeh, I.; Qi, J. Comparative assessment of grassland degradation dynamics in response to climate variation and human activities in China, Mongolia, Pakistan and Uzbekistan from 2000 to 2013. J. Arid Environ. 2016, 135, 164-172. [CrossRef]

37. Gang, C.; Zhou, W.; Chen, Y.; Wang, Z.; Sun, Z.; Li, J.; Qi, J.; Odeh, I. Quantitative assessment of the contributions of climate change and human activities on global grassland degradation. Environ. Earth Sci. 2014, 72, 4273-4282. [CrossRef]

38. Chen, Y.; Yang, K.; He, J.; Qin, J.; Shi, J.; Du, J.; He, Q. Improving land surface temperature modeling for dry land of China. J. Geophys. Res. Space Phys. 2011, 116. [CrossRef]

39. Sheffield, J.; Goteti, G.; Wood, E. Development of a 50-Year High-Resolution Global Dataset of Meteorological Forcings for Land Surface Modeling. J. Clim. 2006, 19, 3088-3111. [CrossRef]

40. Wen, Z.; Wu, S.; Chen, J.; Lü, M. NDVI indicated long-term interannual changes in vegetation activities and their responses to climatic and anthropogenic factors in the Three Gorges Reservoir Region, China. Sci. Total Environ. 2017, 574, 947-959. [CrossRef] [PubMed]

41. Shen, M.; Piao, S.; Chen, X.; An, S.; Fu, Y.H.; Wang, S.; Cong, N.; Janssens, I.A. Strong impacts of daily minimum temperature on the green-up date and summer greenness of the Tibetan Plateau. Glob. Chang. Biol. 2016, 22, 3057-3066. [CrossRef] [PubMed]

42. Yuan, L.H.; Jiang, W.G.; Shen, W.M.; Liu, Y.H.; Wang, W.J.; Tao, L.L.; Zheng, H.; Liu, X.F. The spatio-temporal variations of vegetation cover in the Yellow River Basin from 2000 to 2010. Acta Ecol. Sin. 2013, 33, 7798-7806. 
43. Chen, C.; Park, T.; Wang, X.; Piao, S.; Xu, B.; Chaturvedi, R.K.; Fuchs, R.; Brovkin, V.; Ciais, P.; Fensholt, R.; et al. China and India lead in greening of the world through land-use management. Nat. Sustain. 2019, 2, 122-129. [CrossRef] [PubMed]

44. Fan, N.; Xie, G.D.; Zhang, C.S.; Chen, L.; Cheng, S.K. Spatial-temporal dynamic changes of vegetation cover in Lancang river basin during 2001-2010. Resour. Sci. 2012, 34, 1222-1231.

45. Yin, H.; Pflugmacher, D.; Li, A.; Li, Z.; Hostert, P. Land use and land cover change in Inner Mongolia-understanding the effects of China's re-vegetation programs. Remote Sens. Environ. 2018, 204, 918-930. [CrossRef]

46. Running, S.W.; Thornton, P.E.; Nemani, R.; Glassy, J.M. Global Terrestrial Gross and Net Primary Productivity from the Earth Observing System. In Methods in Ecosystem Science; Sala, O.E., Jackson, R.B., Mooney, H.A., Howarth, R.W., Eds.; Springer: New York, NY, USA, 2000.

47. Chen, P.F. Monthly NPP dataset covering China's terrestrial ecosystems at north of $18^{\circ} \mathrm{N}$ (1985-2015). J. Glob. Chang. Data Discov. 2019, 3, 34-41.

48. Potter, C.; Randerson, J.T.; Field, C.B.; Matson, P.A.; Vitousek, P.; Mooney, H.A.; Klooster, S.A. Terrestrial ecosystem production: A process model based on global satellite and surface data. Glob. Biogeochem. Cycles 1993, 7, 811-841. [CrossRef]

49. Feng, Z.W.; Wang, X.K.; Wu, G. Biomass and Productivity of Chinese Forest Ecosystem; Science Press: Beijing, China, 1999. (In Chinese)

50. Wang, P.; Sun, R.; Hu, J.; Zhu, Q.; Zhou, Y.; Li, L.; Chen, J. Measurements and simulation of forest leaf area index and net primary productivity in Northern China. J. Environ. Manag. 2007, 85, 607-615. [CrossRef]

51. Chen, C.D.; Zhu, J.F. The Manual of Forest Biomass in Northeast of China; Chinese Forest Press: Beijing, China, 1989. (In Chinese)

52. Friend, A.D.; Arneth, A.; Kiang, N.Y.; Lomas, M.; Ogée, J.; Roedenbeck, C.; Running, S.W.; Santaren, J.-D.; Sitch, S.; Viovy, N.; et al. FLUXNET and modelling the global carbon cycle. Glob. Chang. Biol. 2007, 13, 610-633. [CrossRef]

53. Wu, C.; Chen, J.M.; Huang, N. Predicting gross primary production from the enhanced vegetation index and photosynthetically active radiation: Evaluation and calibration. Remote Sens. Environ. 2011, 115, 3424-3435. [CrossRef]

54. Lieth, H. Modeling the Primary Productivity of the World. In Ecological Studies; Springer Science and Business Media LLC: Berlin/Heidelberg, Germany, 1975; Volume 14, pp. 237-263.

55. Guo, Q.; Fu, B.; Shi, P.; Cudahy, T.; Zhang, J.; Xu, H. Satellite Monitoring the Spatial-Temporal Dynamics of Desertification in Response to Climate Change and Human Activities across the Ordos Plateau, China. Remote Sens. 2017, 9, 525. [CrossRef]

56. Liu, Y.; Zhang, Z.; Tong, L.; Khalifa, M.; Wang, Q.; Gang, C.; Wang, Z.; Li, J.; Sun, Z. Assessing the effects of climate variation and human activities on grassland degradation and restoration across the globe. Ecol. Indic. 2019, 106, 105504. [CrossRef]

57. Harold Edwin, H. Long-term storage capacity of reservoirs. Trans. Am. Soc. Civil Eng. 1951, 116, 770-799.

58. Mandelbrot, B.B.; Wallis, J.R. Robustness of the rescaled range R/S in the measurement of noncyclic long run statistical dependence. Water Resour. Res. 1969, 5, 967-988. [CrossRef]

59. Qu, S.; Wang, L.; Lin, A.; Yu, D.; Yuan, M.; Li, C. Distinguishing the impacts of climate change and anthropogenic factors on vegetation dynamics in the Yangtze River Basin, China. Ecol. Indic. 2020, 108, 105724. [CrossRef]

60. Gang, C.; Wang, Z.; Zhou, W.; Chen, Y.; Li, J.; Chen, J.; Qi, J.; Odeh, I.; Groisman, P. Assessing the Spatiotemporal Dynamic of Global Grassland Water Use Efficiency in Response to Climate Change from 2000 to 2013. J. Agron. Crop Sci. 2015, 202, 343-354. [CrossRef]

61. Xu, D.; Li, C.; Song, X.; Ren, H. The dynamics of desertification in the farming-pastoral region of North China over the past 10years and their relationship to climate change and human activity. Catena 2014, 123, 11-22. [CrossRef]

62. Zhou, W.; Gang, C.; Zhou, L.; Chen, Y.; Li, J.; Ju, W.; Odeh, I. Dynamic of grassland vegetation degradation and its quantitative assessment in the northwest China. Acta Oecol. 2014, 55, 86-96. [CrossRef]

63. Xu, D.; Kang, X.; Zhuang, D.; Pan, J. Multi-scale quantitative assessment of the relative roles of climate change and human activities in desertification-A case study of the Ordos Plateau, China. J. Arid Environ. 2010, 74, 498-507. [CrossRef] 
64. Huang, K.; Zhang, Y.-J.; Zhu, J.; Liu, Y.; Zu, J.; Zhang, J. The Influences of Climate Change and Human Activities on Vegetation Dynamics in the Qinghai-Tibet Plateau. Remote Sens. 2016, 8, 876. [CrossRef]

65. Tian, H.; Cao, C.; Chen, W.; Bao, S.; Yang, B.; Myneni, R. Response of vegetation activity dynamic to climatic change and ecological restoration programs in Inner Mongolia from 2000 to 2012. Ecol. Eng. 2015, 82, 276-289. [CrossRef]

66. Horion, S.; Cornet, Y.; Erpicum, M.; Tychon, B. Studying interactions between climate variability and vegetation dynamic using a phenology based approach. Int. J. Appl. Earth Obs. Geoinf. 2013, 20, $20-32$. [CrossRef]

67. Zhang, C.; Wang, X.; Li, J.; Hua, T. Roles of climate changes and human interventions in land degradation: A case study by net primary productivity analysis in China's Shiyanghe Basin. Environ. Earth Sci. 2011, 64, 2183-2193. [CrossRef]

68. Zhou, W.; Gang, C.; Zhou, F.; Li, J.; Dong, X.; Zhao, C. Quantitative assessment of the individual contribution of climate and human factors to desertification in northwest China using net primary productivity as an indicator. Ecol. Indic. 2015, 48, 560-569. [CrossRef]

69. Liu, Y.; Wang, Q.; Zhang, Z.; Tong, L.; Wang, Z.; Li, J. Grassland dynamics in responses to climate variation and human activities in China from 2000 to 2013. Sci. Total Environ. 2019, 690, 27-39. [CrossRef]

70. Chen, Y.; Mu, S.; Sun, Z.; Gang, C.; Li, J.; Padarian, J.; Groisman, P.; Chen, J.; Li, S. Grassland Carbon Sequestration Ability in China: A New Perspective from Terrestrial Aridity Zones. Rangel. Ecol. Manag. 2016, 69, 84-94. [CrossRef]

71. Arneth, A.; Kelliher, F.M.; McSeveny, T.M.; Byers, J.N. Net ecosystem productivity, net primary productivity and ecosystem carbon sequestration in a Pinus radiata plantation subject to soil water deficit. Tree Physiol. 1998, 18, 785-793. [CrossRef] [PubMed]

72. Bai, Y.; Wu, J.; Xing, Q.; Pan, Q.; Huang, J.; Yang, D.; Han, X. Primary production and rain use efficiency across a precipitation gradient on the mongolia plateau. Ecology 2008, 89, 2140-2153. [CrossRef]

73. Mowll, W.; Blumenthal, D.M.; Cherwin, K.; Smith, A.; Symstad, A.J.; Vermeire, L.; Collins, S.L.; Smith, M.D.; Knapp, A.K. Climatic controls of aboveground net primary production in semi-arid grasslands along a latitudinal gradient portend low sensitivity to warming. Oecologia 2015, 177, 959-969. [CrossRef] [PubMed]

74. Zheng, Y.; Xie, Z.; Robert, C.; Jiang, L.; Shimizu, H. Did climate drive ecosystem change and induce desertification in Otindag sandy land, China over the past 40 years? J. Arid Environ. 2006, 64, 523-541. [CrossRef]

75. Zeng, B.; Yang, T.-B. Impacts of climate warming on vegetation in Qaidam Area from 1990 to 2003. Environ. Monit. Assess. 2007, 144, 403-417. [CrossRef] [PubMed]

76. Zhao, M.; Running, S.W. Drought-Induced Reduction in Global Terrestrial Net Primary Production from 2000 Through 2009. Science 2010, 329, 940-943. [CrossRef] [PubMed]

77. Cai, H.; Yang, X.; Xu, X. Human-induced grassland degradation/restoration in the central Tibetan Plateau: The effects of ecological protection and restoration projects. Ecol. Eng. 2015, 83, 112-119. [CrossRef]

78. Wang, Z.; Zhang, Y.; Yang, Y.; Zhou, W.; Gang, C.; Zhang, Y.; Li, J.; An, R.; Wang, K.; Odeh, I.; et al. Quantitative assess the driving forces on the grassland degradation in the Qinghai-Tibet Plateau, in China. Ecol. Inform. 2016, 33, 32-44. [CrossRef]

79. Mu, S.; Zhou, S.; Chen, Y.; Li, J.; Ju, W.; Odeh, I. Assessing the impact of restoration-induced land conversion and management alternatives on net primary productivity in Inner Mongolian grassland, China. Glob. Planet. Chang. 2013, 108, 29-41. [CrossRef]

(C) 2020 by the authors. Licensee MDPI, Basel, Switzerland. This article is an open access article distributed under the terms and conditions of the Creative Commons Attribution (CC BY) license (http://creativecommons.org/licenses/by/4.0/). 